UNIVERSIDADE DE SÃO PAULO

FACULDADE DE MEDICINA DE RIBEIRÃO PRETO

\author{
AVALIAÇÃO DA PRÁTICA TRANSFUSIONAL \\ INTRA-OPERATÓRIA \\ NO SERVIÇO DE ANESTESIOLOGIA DO HOSPITAL DAS \\ CLÍNICAS DA FACULDADE DE MEDICINA DE RIBEIRÃO PRETO
}

Marco Aurélio Beloto de Souza

RIBEIRÃO PRETO 
UNIVERSIDADE DE SÃO PAULO

FACULDADE DE MEDICINA DE RIBEIRÃO PRETO

\section{AVALIAÇÃO DA PRÁTICA TRANSFUSIONAL INTRA-OPERATÓRIA \\ NO SERVIÇO DE ANESTESIOLOGIA DO HOSPITAL DAS \\ CLÍNICAS DA FACULDADE DE MEDICINA DE RIBEIRÃO PRETO}

Dissertação de Mestrado apresentada à Faculdade de Medicina de

Ribeirão Preto, da Universidade de São Paulo, para obtenção do título de Mestre. Área de Concentração: Clínica Cirúrgica.

Aluno: Marco Aurélio Beloto de Souza

Orientador: Prof. Dr. Luís Vicente Garcia

RIBEIRÃO PRETO 


\title{
DEDICATÓRIA
}

\author{
À ROSIANE, \\ Minha esposa, \\ Pelo amor, compreensão e incentivo.
}

A meus pais OLIVAL e JEANETE

Pela formação e apoio. 


\section{AGRADECIMENTOS}

Ao Prof. Dr. Luís Vicente Garcia, meu orientador, pela confiança depositada.

Ao Dr. Antonio Carlos de Souza, pela amizade, apoio e colaboração nos plantões.

Às secretárias do Serviço de Anestesiologia Silvia Caçador F. de Freitas, Luzia Moura de Godói e Maria Rita Próspero Lima pela paciência e auxílio com as fichas de anestesia.

À Sra. Nádia de Araújo Miguel e às bioquímicas do Hospital Universitário, pelo manuseio das amostras sanguíneas coletadas para a confecção do trabalho inicial para a dissertação de mestrado e que não foi concluído em tempo hábil..

Às secretárias Márcia Baratela Fonseca, Laucéia Conrado S. Porcincula, e Malene Lúcio, pela boa vontade e apoio no manuseio dos dados.

Aos colegas do Serviço de Anestesiologia do Hospital Universitário pela compreensão e apoio. 
RESUMO 


\section{RESUMO}

\section{AVALIAÇÃO DA PRÁTICA TRANSFUSIONAL INTRA-OPERATÓRIA NO SERVIÇO DE ANESTESIOLOGIA DO HOSPITAL DAS CLÍNICAS DA FACULDADE DE MEDICINA DE RIBEIRÃO PRETO}

Foram revisadas 10.918 fichas de anestesia e respectivos prontuários médicos de pacientes submetidos à anestesia no Hospital das Clínicas da Faculdade de Medicina de Ribeirão Preto da Universidade de São Paulo, no ano de1999, com o objetivo de avaliar as condutas frente à transfusão sanguínea.

A transfusão sanguínea foi realizada em 809 (7,40\%) pacientes. Houve relação entre a incidência de transfusão e a duração do procedimento cirúrgico, mas não foi possível estabelecer esta relação para as diferentes técnicas anestésicas. Os pacientes pediátricos e os geriátricos foram os que, proporcionalmente, tiveram maior taxa de transfusão.

O Serviço de Anestesiologia do Hospital das Clínicas de Ribeirão Preto não apresenta um protocolo para a indicação de transfusão sanguínea. 


\section{SUMÁRIO}

\section{RESUMO}

PÁG.

1. INTRODUÇÃO.........................................................................

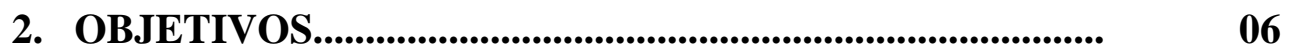

3. CASUÍSTICA E MÉTODO......................................................

4. RESULTADOS.......................................................................... 12

5. DISCUSSÃO

6. CONCLUSÕES...................................................................

7. REFERÊNCIAS BIBLIOGRÁFICAS........................................ 52

SUMMARY 


\section{INTRODUÇÃO}




\section{1 - INTRODUÇÃO}

O homem sempre foi fascinado pelo sangue. Os antigos egípcios banhavam-se nele. Gladiadores romanos e aristocratas bebiam-no. Autores e dramaturgos usavam-no como tema e o homem moderno o transfunde. A trajetória para uma técnica de transfusão eficiente, segura e sem complicações foi longa e árdua. Muitos progressos ocorreram nos últimos 20 anos (HARMENING-PITIGLIO., 1992).

Até a doutrina da circulação do sangue ser formulada por Harvey, em 1616, o conceito de transfusão de sangue não tinha nenhum fundamento lógico. Depois da aceitação de que o sangue circulava e que o espaço intravascular poderia ser preenchido com fluidos provenientes de fora do organismo, a idéia da transfusão sangüínea floresceu. No início, foram realizadas várias transfusões sangüíneas, contudo, de forma bastante empírica. Há relatos de transfusão de animal para homem e homem para homem nos anos de 1666 e 1667. Nessa época, o insucesso das transfusões era uma constante, devido a inúmeros fatores, principalmente a incompatibilidade das transfusões inter-espécies. (Porter, 1996)

No início do século $\mathrm{XX}$ as transfusões eram ainda arriscadas e realizadas de forma direta, ou seja, de doador para receptor, sem o armazenamento do sangue (HARMENING-PITIGLIO., 1992). Em 1901, KARL LANDSTEINER descobriu o grupo sangǘneo ABO e conseguiu explicar algumas das reações transfusionais que ocorriam. Contudo, havia ainda um grande desafio para o aperfeiçoamento das transfusões: o armazenamento do sangue.

O pioneiro no estudo dos anticoagulantes foi Braxton Hicks, que recomendou o uso do fosfato de sódio. Desde então, a conservação do sangue passou a ter atenção especial nas pesquisas. Em 1914, Hustin relatou o emprego de citrato de sódio e glicose e Rous e Turner, em 1916, usaram citrato e dextrose (Porter, 1996).

A necessidade de pessoal treinado suscitou uma nova atividade médica com os Serviços de Transfusão Sangüínea, dos quais o primeiro foi o Voluntary Service de Londres, em 1921. No Brasil, no Rio de Janeiro, serviço semelhante foi fundado por Rosa Martins, Heraldo Maciel e Afonso Ratto, na década de trinta. Com o 
desenvolvimento de técnicas para a preservação do sangue, os Serviços de Transfusão Sangüínea deram lugar aos Bancos de Sangue.

A integridade das células vermelhas do sangue pela sua importância no transporte de oxigênio é tema de constante aprimoramento, sobretudo nas áreas do seu metabolismo que são cruciais para sua função e sobrevida: a membrana da hemácia, a função e estrutura da hemoglobina e a energética celular. A preocupação em minimizar as lesões de armazenamento das hemácias levou ao desenvolvimento de novos anticoagulantes e conservantes: ACD - citrato dextrose ácido, desenvolvido em 1943 por Loutit e Mollison; CPD - citrato fosfato dextrose, CPDA-1 que é o citrato fosfato dextrose com uma suplementação de adenina e com 25\% a mais de glicose, o que possibilitou armazenar concentrado de hemácias por 35 dias com menor queda da concentração do 2,3 DPG. A adição de adenina e fosfato inorgânico no composto preservativo da hemácia melhorou sua capacidade em regenerar ATP. As lesões de armazenamento sobre a membrana das hemácias eram graves quando o sangue era armazenado em frascos de vidro e administrado por meio de tubos de borracha. Tais lesões foram minimizadas com o uso de bolsas de cloreto de polivinila que contêm di-2-etil-hexilfitalato (DEHP) como um plastificador, o que diminuiu as alterações morfológicas da hemácia.

Para o anestesiologista, é de vital importância uma avaliação mais exata possível das perdas sangüíneas do paciente durante uma cirurgia. Essa mensuração pode ser feita por métodos diretos (gravimétrico, volumétrico, colorimétrico) e/ou métodos indiretos ou clínicos, que são largamente utilizados: pressão arterial, débito urinário, freqüência cardíaca, intensidade de bulhas cardíacas, pressão venosa central, enchimento de pulso e coloração de pele e mucosas (FELÍCIO, 1980).

A perda aguda de sangue é, sem dúvida, a indicação mais comum para o anestesiologista iniciar a transfusão. No passado, devido à escassez de métodos para se controlar a hemorragia, a maioria dos procedimentos cirúrgicos acarretava perda de grande volume de sangue e a transfusão sangüínea, por consegüinte, era utilizada rotineiramente. Na atualidade, devido ao desenvolvimento de instrumentos para a realização da hemostasia e ao aprimoramento da técnica cirúrgica, procedimentos cirúrgicos mais invasivos e extensos podem ser realizados sem grande perda sangüínea. Mesmo assim, em alguns tipos de procedimentos, a transfusão ainda ocorre com grande freqüência. 
A transfusão não se resume somente em administrar concentrado de hemácias ou sangue total; refere-se, também, à infusão de outros componentes e derivados sangüíneos como o plasma, as plaquetas e a albumina.

A transfusão de sangue total, muito utilizada no passado, foi perdendo espaço para a transfusão de frações do sangue, eficiente quando bem indicada e menos onerosa, pois um único doador pode beneficiar mais de um receptor. Concatenando esta idéia de utilizar terapias específicas para cada distúrbio, poupando o uso abusivo e inadequado do sangue total, CURCIO \& SOUZA (1993) revisaram os critérios de uso dos componentes sangüíneos: 1) sangue total está indicado em situações de hemorragia aguda grave; 2) concentrado de hemácias: para pacientes com anemia sintomática não responsiva às terapias convencionais e para oxigenar os tecidos em caso de hemorragia aguda de $15 \%$ ou mais do volume estimado e com risco de sobrecarga circulatória; 3) concentrado de plaquetas para pacientes com trombocitopenia grave com sangramento, profilaticamente nos pacientes com menos de 20.000 plaquetas/mm3 e nos casos de hemorragia intensa com menos de 50.000 plaquetas/mm3; 4) plasma fresco congelado está indicado no tratamento da púrpura trombocitopênica trombótica, correção da deficiência dos fatores de coagulação, antitrombina III, fatores II, V, VII, IX, X, XI ou deficiência da proteína C ou S; sangramento agudo com tempo de protrombina e/ou tempo de tromboplastina parcial aumentados; nos casos de sangramento em pacientes com doenças hepáticas, deficiência de vitamina $\mathrm{K}$ e coagulopatia intravascular disseminada. A solução de albumina, um hemoderivado sangüíneo, é responsável por $80 \%$ do poder oncótico do plasma, portanto é usada no tratamento de hipovolemia, na reposição extensa de grandes queimados, na prática da hemodiluição aguda normovolêmica e nos casos de hipoalbuminemia.

Apesar de ser o anestesiologista o responsável pela indicação da transfusão sangüínea no período intra-operatório, nem sempre ele toma essa decisão sozinho. Muitas vezes é o próprio cirurgião, que ao ver sangramento profuso e sem possibilidade de controle imediato, solicita ao anestesiologista o início da transfusão sangüínea. Mesmo com a existência de protocolos que definem de forma precisa, as indicações para transfusão sangüínea, suspeita-se que seu número seja maior do que o necessário. Este trabalho foi realizado com o intuito de investigar essa suspeita e analisar, de 
maneira global, a prática transfusional no Serviço de Anestesiologia do Hospital das Clínicas da Faculdade de Medicina de Ribeirão Preto. 


\section{OBJETIVO}




\section{2 - OBJETIVO}

Analisar a prática transfusional no Serviço de Anestesiologia do Hospital das Clínicas da Faculdade de Medicina de Ribeirão Preto. 


\section{CASUÍSTICA E MÉTODO}




\section{3 - CASUÍSTICA E MÉTODO}

\section{CASUÍSTICA}

Foram revisadas todas as fichas de anestesia de todos os procedimentos anestésicos realizados no Hospital das Clínicas (campus) da Faculdade de Medicina de Ribeirão Preto, no período de 01 de janeiro a 31 de dezembro de 1999. A coleta dos dados foi feita diretamente da ficha de anestesia e quando necessário, informações adicionais foram buscadas no prontuário do paciente. O material que serviu para a coleta dos dados estava arquivado na Secretaria do Serviço de Anestesiologia ou no Serviço de Arquivo Médico e Estatística.

As fichas de anestesia de procedimentos anestésicos em que se realizou a administração de algum componente sangüíneo proveniente do banco de sangue foram separadas das demais e serviram para a coleta da maioria dos dados utilizados neste trabalho.

\section{DADOS GERAIS}

Os prontuários e as fichas foram revistas segundo um protocolo que continha os seguintes dados:

a) Identificação:

nome, idade e número do prontuário do paciente.

b) Faixa etária:

recém-nascido (zero a 30 dias), lactente (mais de 30 dias e menos de 1 ano), criança (entre 1 ano e 12 anos), adulto (mais de 12 e menos de 65 anos) ou geriátrico (mais de 65 anos). 
c) Data do procedimento:

dia e mês em que o procedimento foi realizado.

d) Procedimento cirúrgico e especialidade a que pertence

e) Tipo de Anestesia:

raquianestesia, peridural, geral, combinada (raquianestesia + peridural), bloqueio de membro superior e anestesia local. Quando houve associação entre qualquer técnica de anestesia regional e a anestesia geral, considerou-se, para efeito de contagem, exclusivamente a anestesia geral.

f) Duração do ato anestésico:

tempo decorrido entre a indução anestésica e o término da anestesia, assinalado pelo anestesiologista responsável pelo procedimento.

g) Regime cirúrgico:

eletivo, para cirurgias agendadas na escala cirúrgica normal do Bloco Cirúrgico e de urgência para todas as demais cirurgias realizadas.

\section{POPULAÇÃO TRANSFUNDIDA}

a) Transfusão ou não de algum componente sangüíneo.

b) Tipo de componente sangüíneo recebido e volume transfundido:

albumina, papa de hemácias, plasma, crioprecipitado, sangue total e plaquetas. 


\section{DADOS LABORATORIAIS}

a) Taxa de hemoglobina e hematócrito:

taxa de hemoglobina e valor do hematócrito quantificados no período pré-operatório ou intraoperatório, antes da transfusão de papa de hemácias.

b) Contagem de plaquetas:

contagem de plaquetas no período pré-operatório ou intra-operatório, antes da transfusão de concentrado de plaquetas. 


\section{RESULTADOS}




\section{RESULTADOS}

A revisão dos prontuários e respectivas fichas de anestesia permitiu a coleta dos dados que serão apresentados a seguir:

No ano de 1999 foram realizadas, no Hospital das Clínicas de Ribeirão Preto (campus), 10918 anestesias para as mais variadas especialidades cirúrgicas. Em 809 destes procedimentos (7,40\%), os pacientes receberam algum tipo de componente sangüíneo e/ou derivado sangüíneo durante o período intra-operatório. Essas especialidades cirúrgicas bem como a quantidade de cirurgias que cada uma delas realizou e a incidência de transfusão estão demonstradas na Tabela 1.

Tabela 1. Procedimentos cirúrgicos por especialidade e incidência de transfusão sangüínea no ano de 1999 no HCFMRPUSP

\begin{tabular}{lcccc}
\hline $\begin{array}{c}\text { Especialidade } \\
\text { (Disciplinas) }\end{array}$ & $\begin{array}{c}\text { Número de } \\
\text { Cirurgias }\end{array}$ & $\begin{array}{c}\text { \% } \\
\text { do Total }\end{array}$ & $\begin{array}{c}\text { Cirurgias } \\
\text { com } \\
\text { transfusão }\end{array}$ & $\begin{array}{c}\text { \% de pacientes } \\
\text { transfundidos }\end{array}$ \\
\hline Ginecologia & 1573 & 14,40 & 53 & 3,36 \\
Ortopedia & 1182 & 10,82 & 83 & 7,02 \\
Gastro Procto Geral. & 1179 & 10,79 & 151 & 12,80 \\
Obstetrícia & 1145 & 10,48 & 12 & 1,04 \\
Oftalmologia & 965 & 8,83 & 2 & 0,20 \\
Proc. Diagnósticos & 833 & 7,62 & 0 & 0 \\
Otorrinolaringologia & 798 & 7,30 & 7 & 0,87 \\
Urologia & 625 & 5,72 & 83 & 13,28 \\
Neurocirurgia & 495 & 4,53 & 96 & 19,39 \\
Vascular & 487 & 4,46 & 46 & 9,44 \\
Pediatria & 461 & 4,22 & 15 & 3,25 \\
Tórax & 460 & 4,21 & 227 & 49,34 \\
Cabeça e Pescoço & 334 & 3,05 & 22 & 6,58 \\
Plástica & 173 & 1,58 & 4 & 2,31 \\
Hematologia* & 18 & 0,16 & 8 & 44,44 \\
Outras & 190 & 1,74 & 0 & 0 \\
\hline Total & $\mathbf{1 0 9 1 8}$ & $\mathbf{1 0 0 , 0}$ & $\mathbf{8 0 9}$ & $\mathbf{7 , 4 0 \%}$ \\
\hline \multicolumn{1}{c}{$*$ doador de medula óssea } & & &
\end{tabular}

* doador de medula óssea 
Do total de pacientes submetidos à cirurgia, 809 (7,40\%) receberam, durante o período intra-operatório, algum componente sangüíneo e ou hemoderivado (Figura 1).

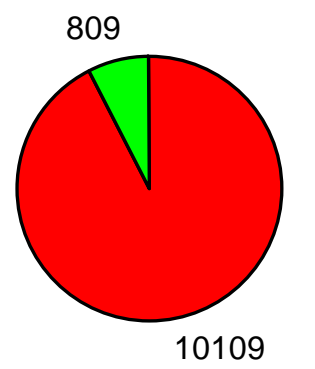

Fig. 1 Relação entre número de pacientes que receberam e pacientes que não receberam hemoderivados e/ou componentes sangüíneos durante o período intra-operatório no ano de 1999 no HCFMRPUSP.

Os resultados da Tabela 1 estão representados,

graficamente, nas figuras 2, 3 e 4 .

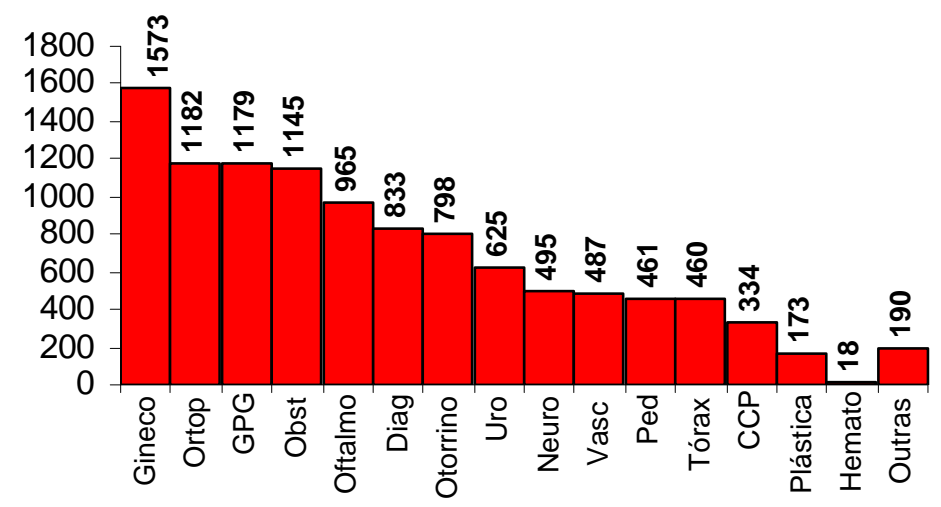

Fig. 2 Número de procedimentos, por disciplina, no ano de 1999, no HCFMRPUSP 


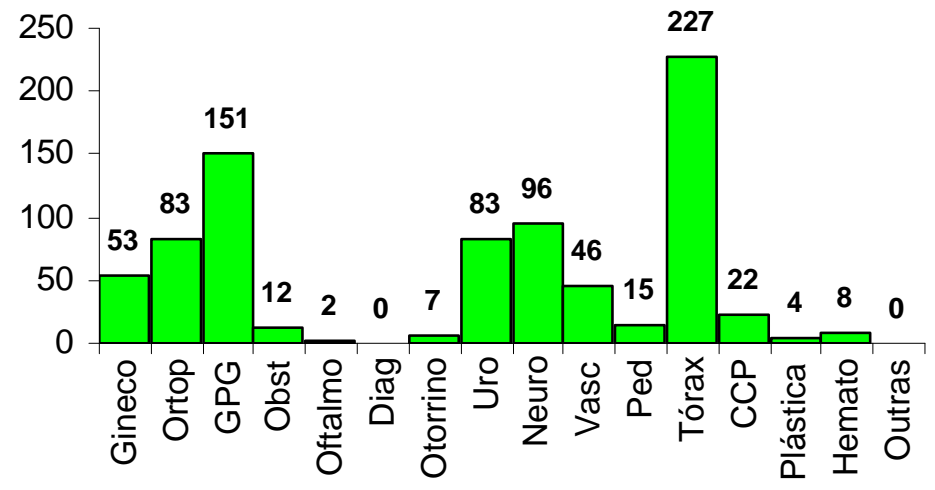

Fig. 3 Número de pacientes, por disciplina, que receberam hemoderivado e/ou componente sangüíneo durante o período intra-operatório, no ano de 1999 no HCFMRPUSP.

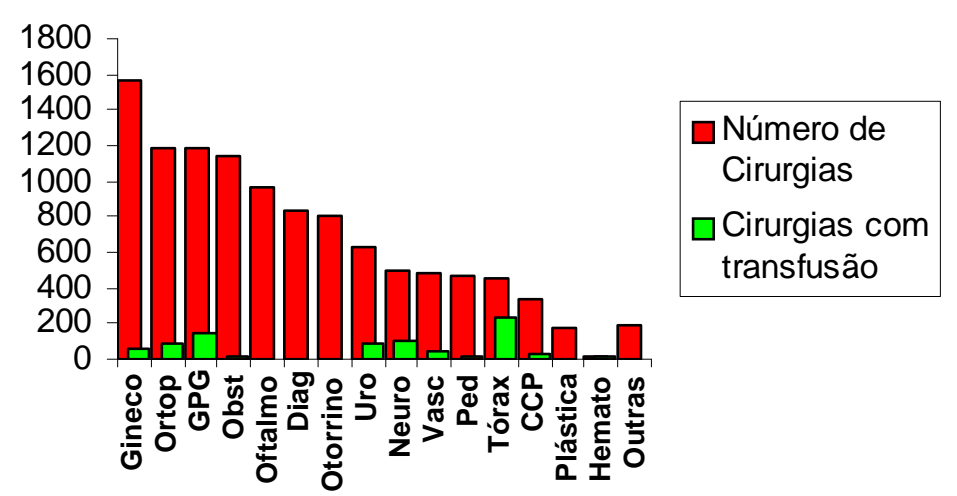

Fig. 4 Número de cirurgias realizadas por disciplina e número de pacientes que receberam hemoderivado e/ou componente sangüíneo durante o período intra-operatório, no ano de 1999 no HCFMRPUSP.

Os tipos de cirurgias que cada especialidade realizou, bem como aquelas que necessitaram de transfusão de algum componente sangüíneo podem ser vistas nas tabelas 2 a 13. 


\section{Tabela 2 Procedimentos realizados pelo Serviço de Ginecologia e Obstetrícia do HCFMRPUSP e incidência de transfusão sangüínea intra- operatória no ano de 1999.}

\begin{tabular}{|c|c|c|c|}
\hline Procedimentos & $\begin{array}{c}\text { Número de } \\
\text { Procedimentos }\end{array}$ & $\begin{array}{l}\text { Procedimentos c/ } \\
\text { Transfusão }\end{array}$ & $\begin{array}{l}\text { \% de pacientes } \\
\text { transfundidos por } \\
\text { procedimento }\end{array}$ \\
\hline Biópsias & 6 & 0 & 0 \\
\hline Burch & 37 & 0 & 0 \\
\hline Curetagem + curagem & 27 & 2 & 7,40 \\
\hline CPPA + P ou perineoplastia & 86 & 0 & 0 \\
\hline Correção de fístula vaginal & 7 & 0 & 0 \\
\hline Conização de colo uterino & 7 & 1 & 14,28 \\
\hline Combinada (mais de uma cirurgia) & 180 & 0 & 0 \\
\hline Curetagem de mola hidantiforme & 1 & 0 & 0 \\
\hline Césio Moldagem & 8 & 0 & 0 \\
\hline Captação de ovócitos & 151 & 3 & 1,99 \\
\hline Cerclagem uterina & 4 & 0 & 0 \\
\hline Condiloma (exerese / cauterização) & 25 & 0 & 0 \\
\hline Dermolipectomia & 2 & 0 & 0 \\
\hline Drenagem de abcessos & 5 & 0 & 0 \\
\hline Exerese de cisto de Bartholin & 2 & 0 & 0 \\
\hline Exame no Centro Cirúrgico & 348 & 0 & 0 \\
\hline Histerectomia & 230 & 15 & 6,52 \\
\hline Laparotomia exploradora & 35 & 6 & 17,14 \\
\hline Laqueadura tubárea & 92 & 0 & 0 \\
\hline Lise-sinéquia & 1 & 0 & 0 \\
\hline Mastectomia + mastoplastia & 118 & 0 & 0 \\
\hline Miomectomia & 13 & 1 & 7,69 \\
\hline Marsupialização & 1 & 0 & 0 \\
\hline Neovaginoplastia & 3 & 0 & 0 \\
\hline Ooforectomia & 11 & 4 & 36,36 \\
\hline Pan-Histerectomia & 26 & 1 & 3,85 \\
\hline Nódulo de mama e quadrantectomia & 35 & 0 & 0 \\
\hline Retirada de TU de ovário & 2 & 0 & 0 \\
\hline Ressutura de parede & 9 & 0 & 0 \\
\hline Retirada de cisto + salpingectomia & 20 & 0 & 0 \\
\hline Werthein-Meigs & 25 & 19 & 76,00 \\
\hline Esvaziamento axilar & 14 & 0 & 0 \\
\hline Outros & 41 & 3 & 7,31 \\
\hline Parto normal com analgesia & 1040 & 2 & 0,19 \\
\hline Cesariana & 106 & 10 & 9,43 \\
\hline Total & 2718 & 66 & 2,42 \\
\hline
\end{tabular}




\section{Tabela 3 Procedimentos cirúrgicos realizados pelo Serviço de Ortopedia do HCFMRPUSP e incidência de transfusão sangüínea intra- operatória no ano de 1999.}

\begin{tabular}{lccc}
\hline \multicolumn{1}{c}{ Procedimentos } & $\begin{array}{c}\text { Número de } \\
\text { Procedimentos }\end{array}$ & $\begin{array}{c}\text { Procedimentos c/ } \\
\text { Transfusão }\end{array}$ & $\begin{array}{c}\text { \% } \\
\text { transfundidos } \\
\text { por procedimento }\end{array}$ \\
\hline Amputação de membro inferior & 9 & 0 & 0 \\
Biópsia & 18 & 3 & 16,67 \\
Osteossíntese braço + antebraço & 74 & 0 & 0 \\
Artrodese de colune & 116 & 31 & 26,72 \\
Curativos & 50 & 0 & 0 \\
Correção de paralisia obstétrica & 2 & 0 & 0 \\
Descompressão de nervo tibial & 3 & 0 & 0 \\
Desbridamentos & 16 & 0 & 0 \\
Drenagem de abcessos & 20 & 0 & 0 \\
Exame do Centro Cirúrgico & 5 & 0 & 0 \\
Enxertos & 38 & 0 & 0 \\
Femur & 83 & 7 & 8,43 \\
Gesso (troca ou colocação) & 5 & 1 & 20,00 \\
Joelho (quadriceptoplastia) & 171 & 2 & 1,17 \\
Cirurgia de Mão & 98 & 0 & 0 \\
Múltiplas fraturas & 1 & 0 & 0 \\
Cirurgia de Ombro & 48 & 0 & 0 \\
Punção de artrite séptica & 10 & 0 & 0 \\
Cirurgia do Pé & 85 & 0 & 0 \\
Osteossíntese de tíbia & 75 & 0 & 0 \\
Cirurgia de Quadril & 101 & 28 & 27,72 \\
Retirada de material de síntese & 83 & 7 & 8,43 \\
Torcicolo congênito & 1 & 0 & 0 \\
Outras & 70 & 4 & $\mathbf{7 , 0 2}$ \\
\hline \multicolumn{1}{c}{ Total } & $\mathbf{1 1 8 2}$ & $\mathbf{8 3}$ & \\
\hline & & & 0 \\
\hline
\end{tabular}


Tabela 4 Procedimentos cirúrgicos realizados pelo Serviço de Cirurgia do HCFMRPUSP (Disciplinas de Gastrocirurgia, Proctologia e Geral) e incidência de transfusão sangüínea intra-operatória no ano de 1999.

\begin{tabular}{|c|c|c|c|}
\hline Procedimentos & $\begin{array}{c}\text { Número de } \\
\text { Procedimentos }\end{array}$ & $\begin{array}{c}\text { Procedimentos } \\
\text { c/ } \\
\text { Transfusão }\end{array}$ & $\begin{array}{c}\% \text { de pacientes } \\
\text { transfundidos } \\
\text { por procedimento }\end{array}$ \\
\hline Amputação períneo-abdominal & 7 & 3 & 42,86 \\
\hline Apendicectomia & 15 & 0 & 0 \\
\hline Amputação de membros & 2 & 0 & 0 \\
\hline Biópsias & 29 & 0 & 0 \\
\hline Colecistectomia & 238 & 2 & 0,84 \\
\hline Coledocoduodenostomia & 2 & 0 & 0 \\
\hline Colectomia ou hemicolectomia & 66 & 10 & 15,15 \\
\hline Correção de prolapso retal & 9 & 0 & 0 \\
\hline Desconexão ázigo-portal & 1 & 1 & 100 \\
\hline Duhamell Haddad & 2 & 0 & 0 \\
\hline Duodenopancreatectomia & 2 & 0 & 0 \\
\hline DVB - Derivação bílio-digestiva & 16 & 3 & 18,75 \\
\hline Deiscência de sutura (ressutura) & 14 & 5 & 35,71 \\
\hline Drenagem de abscessos & 7 & 0 & 0 \\
\hline Esfinterotomia & 8 & 0 & 0 \\
\hline Esofagectomia & 17 & 8 & 47,06 \\
\hline Esplenectomia & 16 & 7 & 43,75 \\
\hline Fistulectomia & 66 & 0 & 0 \\
\hline Gastrectomia & 36 & 16 & 44,44 \\
\hline Gastrostomia & 7 & 0 & 0 \\
\hline Hepatectomia & 14 & 13 & 92,26 \\
\hline Heller & 27 & 0 & 0 \\
\hline Hemorroidectomia & 110 & 0 & 0 \\
\hline Hepatoduodenoanastomose & 1 & 0 & 0 \\
\hline Herniorrafia inguinal + incisional & 179 & 0 & 0 \\
\hline Herniorrafia hiatal & 31 & 0 & 0 \\
\hline Ileostomia & 3 & 0 & 0 \\
\hline Instalação ou retirada de cateter & 11 & 0 & 0 \\
\hline Laparotomia ou lombotomia & 116 & 73 & 62,93 \\
\hline Jejunostomia & 2 & 0 & 0 \\
\hline Prótese esôfago-gástrica & 2 & 0 & 0 \\
\hline Correção de fístula entérica & 1 & 1 & 100 \\
\hline Reconstrução de trânsito & 45 & 0 & 0 \\
\hline Resseç̧ão de condiloma & 14 & 0 & 0 \\
\hline Ressecção de cisto pilonidal & 8 & 0 & 0 \\
\hline Retirada de corpo estranho & 1 & 0 & 0 \\
\hline Ressutura de deiscência & 3 & 2 & 66,67 \\
\hline Vagotomia & 1 & 0 & 0 \\
\hline Outros & 50 & 7 & 14,00 \\
\hline Total & 1179 & 151 & 12,81 \\
\hline
\end{tabular}




\section{Tabela 5 Procedimentos cirúrgicos realizados pelo Serviço de Oftalmologia do HCFMRPUSP e incidência de transfusão sangüínea intra-operatória no ano de 1999.}

\begin{tabular}{|c|c|c|c|}
\hline Procedimentos & $\begin{array}{c}\text { Número de } \\
\text { Procedimentos }\end{array}$ & $\begin{array}{c}\text { Procedimentos } \\
\text { c/ } \\
\text { Transfusão } \\
\end{array}$ & $\begin{array}{l}\text { \% de pacientes } \\
\text { transfundidos p/ } \\
\text { procedimento }\end{array}$ \\
\hline Aponeurose de olho & 4 & 0 & 0 \\
\hline Biópsias & 4 & 0 & 0 \\
\hline Correção de ptose & 26 & 0 & 0 \\
\hline Correção de estrabismo & 156 & 0 & 0 \\
\hline Correção de lagorfalmo & 1 & 0 & 0 \\
\hline Correção de traumas oculares & 13 & 0 & 0 \\
\hline Correção de epibléfaro & 6 & 0 & 0 \\
\hline Cantoplastia & 1 & 0 & 0 \\
\hline Correção prolapso s. conjuntival & 1 & 0 & 0 \\
\hline Dacriocistorrinostomia (DCR) & 46 & 0 & 0 \\
\hline Drenagem de abcessos & 3 & 0 & 0 \\
\hline Descompressão de globo ocular & 18 & 1 & 5,56 \\
\hline Discisão de cápsula & 1 & 0 & 0 \\
\hline Exerese de TU de órbita & 10 & 1 & 10,00 \\
\hline Exerese de TU de pálpebra & 3 & 0 & 0 \\
\hline Exerese de hemangioma & 1 & 0 & 0 \\
\hline Evisceração & 6 & 0 & 0 \\
\hline Exame sob anestesia & 8 & 0 & 0 \\
\hline Enucleação & 6 & 0 & 0 \\
\hline Enxerto de pálpebra & 2 & 0 & 0 \\
\hline Etmoidectomia & 1 & 0 & 0 \\
\hline Facectomia & 439 & 0 & 0 \\
\hline Hugnes & 1 & 0 & 0 \\
\hline Implante de lente intraocular & 9 & 0 & 0 \\
\hline Lifting temporal & 1 & 0 & 0 \\
\hline Orbitotomia & 3 & 0 & 0 \\
\hline Retinopexia & 68 & 0 & 0 \\
\hline Reconstrução de cavidade & 5 & 0 & 0 \\
\hline Retirada de pontos & 1 & 0 & 0 \\
\hline Retirada de corpo estranho & 2 & 0 & 0 \\
\hline Sutura de córnea & 26 & 0 & 0 \\
\hline Sutura de pálpebra & 3 & 0 & 0 \\
\hline Transplante de córnea & 18 & 0 & 0 \\
\hline Outros & 37 & 0 & 0 \\
\hline Suspensão Frontal & 9 & 0 & 0 \\
\hline Trabeculectomia & 26 & 0 & 0 \\
\hline $\begin{array}{r}\text { Total } \\
\end{array}$ & 965 & 2 & 0,21 \\
\hline
\end{tabular}




\begin{tabular}{|c|c|c|c|c|}
\hline Tabela 6 & \multicolumn{4}{|c|}{ 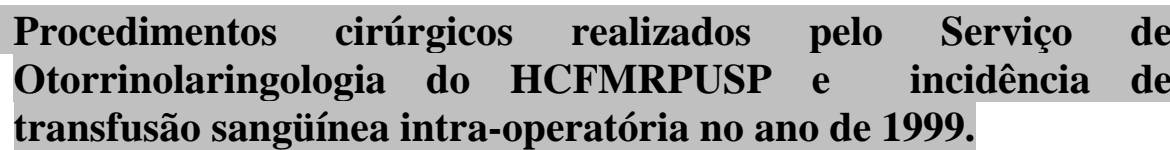 } \\
\hline \multicolumn{2}{|c|}{ Procedimentos } & $\begin{array}{c}\text { Número de } \\
\text { Procedimentos }\end{array}$ & $\begin{array}{l}\text { Procedimentos c/ } \\
\text { Transfusão }\end{array}$ & $\begin{array}{l}\text { \% de pacientes } \\
\text { transfundidos } \\
\text { p/ procedimento }\end{array}$ \\
\hline \multicolumn{2}{|c|}{ Adenoamigdalectomia } & 80 & 0 & 0 \\
\hline \multicolumn{2}{|c|}{ Adenoidectomia } & 104 & 2 & 1,92 \\
\hline \multicolumn{2}{|c|}{ Amigdalectomia } & 22 & 0 & 0 \\
\hline \multicolumn{2}{|c|}{ Colocação de tubos de aeração } & 14 & 0 & 0 \\
\hline \multicolumn{2}{|c|}{ Descompressão de nervo facial } & 1 & 0 & 0 \\
\hline \multicolumn{2}{|c|}{ Drenagem de abcessos } & 4 & 0 & 0 \\
\hline \multicolumn{2}{|c|}{ Estepedectomia } & 20 & 0 & 0 \\
\hline \multicolumn{2}{|c|}{ Epistache (tamponamento) } & 2 & 1 & 50,00 \\
\hline \multicolumn{2}{|c|}{ Fechamento de fístula } & 2 & 0 & 0 \\
\hline \multicolumn{2}{|c|}{ Mastoidectomia } & 44 & 0 & 0 \\
\hline \multicolumn{2}{|c|}{ Microcirurgia de laringe } & 40 & 0 & 0 \\
\hline \multicolumn{2}{|c|}{ Microcirurgia endonasal } & 76 & 0 & 0 \\
\hline \multicolumn{2}{|c|}{ Otoplastia } & 2 & 0 & 0 \\
\hline \multicolumn{2}{|c|}{ Retirada de nódulos (ou pólipos) } & 6 & 0 & 0 \\
\hline \multicolumn{2}{|c|}{ Rinosseptoplastia } & 34 & 0 & 0 \\
\hline \multicolumn{2}{|c|}{ Rinoplastia } & 57 & 1 & 1,75 \\
\hline \multicolumn{2}{|c|}{ Ressecção de membrana } & 1 & 0 & 0 \\
\hline \multicolumn{2}{|c|}{ Septoplastia } & 109 & 0 & 0 \\
\hline \multicolumn{2}{|c|}{ Timpanoplastia } & 142 & 0 & 0 \\
\hline \multicolumn{2}{|c|}{ Turbinectomia } & 10 & 0 & 0 \\
\hline \multicolumn{2}{|c|}{ Outros } & 22 & 3 & 13,64 \\
\hline \multicolumn{2}{|c|}{ Sinusotomia } & 1 & 0 & 0 \\
\hline \multicolumn{2}{|c|}{ Red. Fratura nasal } & 5 & 0 & 0 \\
\hline & otal & 798 & 7 & 0,88 \\
\hline
\end{tabular}


Tabela 7 Procedimentos cirúrgicos realizados pelo Serviço de Urologia do HCFMRPUSP e incidência de transfusão sangǘnea intraoperatória no ano de 1999.

\begin{tabular}{|c|c|c|c|}
\hline Procedimentos & $\begin{array}{c}\text { Número de } \\
\text { Procedimentos }\end{array}$ & $\begin{array}{l}\text { Procedimentos c/ } \\
\text { Transfusão }\end{array}$ & $\begin{array}{l}\text { \% de pacientes } \\
\text { transfundidos } \\
\text { p/ procedimento }\end{array}$ \\
\hline Adrenalectomia & 6 & 3 & 50,00 \\
\hline Biópsias & 6 & 0 & 0 \\
\hline Correção de estenose ureteral & 19 & 0 & 0 \\
\hline Cistectomia & 4 & 2 & 50,00 \\
\hline Correção de JUP & 12 & 0 & 0 \\
\hline Correção de hipospádia & 12 & 0 & 0 \\
\hline Correção de ureterocele & 2 & 0 & 0 \\
\hline Correção de criptorquidia & 6 & 0 & 0 \\
\hline Correção de fístula vésico-cutânea & 9 & 0 & 0 \\
\hline Cistolitotomia & 3 & 0 & 0 \\
\hline Dilatação ureteral & 4 & 0 & 0 \\
\hline Drenagem de hematoma renal & 1 & 0 & 0 \\
\hline Exame sob anestesia & 27 & 0 & 0 \\
\hline Evacuação vesical & 5 & 0 & 0 \\
\hline Hidrocelectomia & 14 & 0 & 0 \\
\hline Herniorrafia & 8 & 0 & 0 \\
\hline Implante de pig-tail & 18 & 0 & 0 \\
\hline Implante de prótese peniana & 10 & 0 & 0 \\
\hline Implante renal & 58 & 18 & 31,03 \\
\hline Lombotomia Exploradora & 8 & 4 & 50,00 \\
\hline Nefroureterectomia & 4 & 0 & 0 \\
\hline Nefrolitomia & 9 & 0 & 0 \\
\hline Nefrectomia & 45 & 19 & 42,22 \\
\hline Orquidopexia & 22 & 0 & 0 \\
\hline Orquiectomia & 13 & 0 & 0 \\
\hline Prostatectomia & 35 & 19 & 54,29 \\
\hline Pielolitotomia & 12 & 0 & 0 \\
\hline Pieloplastia & 6 & 0 & 0 \\
\hline Ressecção tumor vesical & 4 & 0 & 0 \\
\hline RTU de próstata & 79 & 4 & 5,06 \\
\hline RTU vesical & 30 & 1 & 3,33 \\
\hline Ureterolitotomia & 25 & 1 & 4,00 \\
\hline Vesicostomia & 5 & 0 & 0 \\
\hline Vasoamastomose & 5 & 0 & 0 \\
\hline Varicocelectomia & 5 & 0 & 0 \\
\hline Eletrovaporização prostática & 3 & 0 & 0 \\
\hline Adenomectomia & 22 & 4 & 18,18 \\
\hline Outros & 69 & 8 & 11,59 \\
\hline Total & 625 & 83 & 13,28 \\
\hline
\end{tabular}




\begin{tabular}{|c|c|c|c|}
\hline \multirow{2}{*}{\multicolumn{4}{|c|}{$\begin{array}{l}\text { Procedimentos cirúrgicos realizados pelo Serviço de } \\
\text { Neurocirurgia do HCFMMRPUSP e incidência de transfusão } \\
\text { sangüínea intra-operatória no ano de } 1999 \text {. }\end{array}$}} \\
\hline & & & \\
\hline Procedimentos & $\begin{array}{c}\text { Número de } \\
\text { Procedimentos }\end{array}$ & $\begin{array}{l}\text { Procedimentos } \\
\text { c/ } \\
\text { Transfusão }\end{array}$ & $\begin{array}{l}\text { \% de pacientes } \\
\text { transfundidos p/ } \\
\text { procedimento }\end{array}$ \\
\hline Hipofisectomia transesfenoidal & 16 & 1 & 6,25 \\
\hline Artrodese de coluna cervical & 5 & 0 & 0 \\
\hline Anastomose hipoglosso facial & 2 & 0 & 0 \\
\hline Biópsias & 7 & 0 & 0 \\
\hline Cranioplastia & 4 & 0 & 0 \\
\hline Craniot. p/ exerese de tumor & 106 & 38 & 35,85 \\
\hline Craniot.para correção de MAV & 2 & 0 & 0 \\
\hline Craniot. p/ exerese de cisticerco & 6 & 0 & 0 \\
\hline Craniotomia pós-trauma & 1 & 0 & 0 \\
\hline Clipagem de aneurisma & 56 & 18 & 32,14 \\
\hline Correção de mielomeningocele & 10 & 1 & 10,00 \\
\hline Correção de craniestenose & 7 & 5 & 71,43 \\
\hline DVP ou DVE ou revisão & 81 & 0 & 0 \\
\hline Drenagem de abcessos & 6 & 0 & 0 \\
\hline Drenagem de hematomas & 15 & 6 & 40,00 \\
\hline Exerese de TU de coluna lombar & 5 & 2 & 40,00 \\
\hline Termocoagulação & 3 & 0 & 0 \\
\hline Hipofisectomia & 2 & 0 & 0 \\
\hline Laminectomia & 46 & 2 & 4,35 \\
\hline Outros & 16 & 6 & 37,50 \\
\hline Revisão de tumor de medula & 1 & 1 & 100 \\
\hline Revisão de craniotomia & 5 & 5 & 100 \\
\hline Craniotomia (epilepsia) & 91 & 11 & 12,09 \\
\hline Fechamento de fístula liquórica & 2 & 0 & 0 \\
\hline Total & 495 & 96 & 19,39 \\
\hline
\end{tabular}




\begin{tabular}{|c|c|c|c|c|}
\hline Tabela 9 & \multicolumn{4}{|c|}{$\begin{array}{l}\text { Procedimentos cirúrgicos realizados pelo Serviço de Cirurgia } \\
\text { Vascular do HCFMRPUSP e incidência de transfusão sangüínea } \\
\text { intra-operatória no ano de } 1999 \text {. }\end{array}$} \\
\hline \multicolumn{2}{|c|}{ Procedimentos } & $\begin{array}{c}\text { Número de } \\
\text { Procedimentos }\end{array}$ & $\begin{array}{l}\text { Procedimentos c/ } \\
\text { Transfusão }\end{array}$ & $\begin{array}{l}\% \text { de pacientes } \\
\text { transfundidos } \\
\text { p/ procedimento }\end{array}$ \\
\hline \multicolumn{2}{|c|}{ Aneurismectomia } & 21 & 21 & 100 \\
\hline \multicolumn{2}{|c|}{ Amp. de membros inferiores } & 70 & 2 & 2,86 \\
\hline \multicolumn{2}{|c|}{ By pass aorto bifemural } & 7 & 1 & 14,29 \\
\hline \multicolumn{2}{|c|}{ By pass femuro poplíteo } & 30 & 6 & 20,00 \\
\hline \multicolumn{2}{|c|}{ By pass axilo-bifemural } & 1 & 0 & 0 \\
\hline \multicolumn{2}{|c|}{ By pass ilíaca femural } & 5 & 1 & 20,00 \\
\hline \multicolumn{2}{|c|}{ Curativos } & 2 & 2 & 100 \\
\hline \multicolumn{2}{|c|}{ Correção de fístula } & 13 & 0 & 0 \\
\hline \multicolumn{2}{|c|}{ Desbridamentos } & 36 & 4 & 11,11 \\
\hline \multicolumn{2}{|c|}{ Exploração arterial } & 47 & 6 & 12,77 \\
\hline \multicolumn{2}{|c|}{ Endarterectomia (obs. arterial) } & 14 & 0 & 0 \\
\hline \multicolumn{2}{|c|}{ Implante cateter quimioterapia } & 12 & 0 & 0 \\
\hline \multicolumn{2}{|c|}{ Retirada de hemangioma } & 2 & 0 & 0 \\
\hline \multicolumn{2}{|c|}{ Reexploração cirúrgica } & 5 & 1 & 20,00 \\
\hline \multicolumn{2}{|c|}{ Safenectomia uni ou bilateral } & 172 & 0 & 0 \\
\hline \multicolumn{2}{|c|}{ Simpatectomia (oclusão arterial) } & 24 & 0 & 0 \\
\hline \multicolumn{2}{|c|}{ Tireoidectomia } & 12 & 0 & 0 \\
\hline \multicolumn{2}{|c|}{ Tromboembolectomia } & 2 & 0 & 0 \\
\hline \multicolumn{2}{|c|}{ Outros } & 12 & 2 & 16,67 \\
\hline \multicolumn{2}{|c|}{ Total } & 487 & 46 & 9,45 \\
\hline
\end{tabular}



$\begin{array}{ll}\text { Tabela } 10 & \text { Procedimentos cirúrgicos realizados pelo Serviço de Cirurgia } \\ & \text { Pediátrica do HCFMRPUSP e incidência de transfusão } \\ \text { sangǘnea intra-operatória no ano de } 1999 .\end{array}$

\section{Procedimentos Procedimentos Transfusão transfundidos p/} procedimento

\begin{tabular}{|c|c|c|c|}
\hline Amputação de coto de colon & 5 & 0 & 0 \\
\hline Apendicectomia & 2 & 0 & 0 \\
\hline Biópsias & 38 & 1 & 2,63 \\
\hline Colecistectomia & 5 & 0 & 0 \\
\hline Colocação de cateter implantável & 43 & 2 & 4,65 \\
\hline Correção de atresia de esôfago & 10 & 1 & 10,00 \\
\hline Correção de Refluxo & 17 & 0 & 0 \\
\hline Correção de RGE (Nissen) & 17 & 0 & 0 \\
\hline Criptorquídia & 7 & 0 & 0 \\
\hline Derivação de trânsito intestinal & 9 & 0 & 0 \\
\hline Drenagem de abcesso & 5 & 1 & 20,00 \\
\hline Duhamel Haddad & 2 & 0 & 0 \\
\hline Exame no Centro Cirúrgico & 10 & 0 & 0 \\
\hline Exerese de nódulos & 2 & 0 & 0 \\
\hline Exerese de TU & 1 & 0 & 0 \\
\hline Explenectomia & 3 & 0 & 0 \\
\hline Gastrectomia & 1 & 0 & 0 \\
\hline Gastrostomia & 6 & 0 & 0 \\
\hline Herniorrafia hiatal & 2 & 0 & 0 \\
\hline Herniorrafia inguinal & 100 & 0 & 0 \\
\hline Herniorrafia umbelical & 24 & 0 & 0 \\
\hline Imperfuração anal - plástica & 55 & 0 & 0 \\
\hline Laparotomia exploradora & 25 & 6 & 24,00 \\
\hline Onfalocele & 2 & 2 & 100 \\
\hline Orquidopexia & 6 & 0 & 0 \\
\hline Outros & 46 & 2 & 4,35 \\
\hline Plástica de genitália & 5 & 0 & 0 \\
\hline Postectomia (fimose) & 10 & 0 & 0 \\
\hline Punção medular & 1 & 0 & 0 \\
\hline Revisão de gastrostomia & 2 & 0 & 0 \\
\hline Total & 461 & 15 & 3,25 \\
\hline
\end{tabular}


$\begin{array}{ll}\text { Tabela } 11 & \text { Procedimentos cirúrgicos realizados pela Divisão de Cirurgia } \\ & \text { Torácica e Cardiovascular do HCFMRPUSP e incidência de } \\ \text { transfusão sangǘnea intra-operatória no ano de } 1999 .\end{array}$

\begin{tabular}{|c|c|c|c|}
\hline Procedimentos & $\begin{array}{c}\text { Número de } \\
\text { Procedimentos }\end{array}$ & $\begin{array}{c}\text { Procedimentos } \\
\text { c/ } \\
\text { Transfusão }\end{array}$ & $\begin{array}{l}\text { \% de pacientes } \\
\text { transfundidos } \\
\text { p/ procedimento }\end{array}$ \\
\hline Blalock & 13 & 9 & 69,23 \\
\hline Correção de CIA ou CIV & 41 & 22 & 53,66 \\
\hline Correção de valvulopatia & 26 & 7 & 26,92 \\
\hline Correção de PCA & 36 & 2 & 5,56 \\
\hline Colocação ou troca de marcapasso* & 4 & 0 & 0 \\
\hline Drenagem pericárdica & 5 & 4 & 80,00 \\
\hline Pericardiectomia & 4 & 1 & 25,00 \\
\hline Revascularização do miocárdio & 114 & 79 & 69,30 \\
\hline Revisão de toracotomia & 4 & 3 & 75,00 \\
\hline Revisão de esternotomia & 13 & 4 & 30,67 \\
\hline Troca de válvula & 79 & 68 & 86,08 \\
\hline Tetralogia de fallot & 9 & 9 & 100 \\
\hline Aneurismectomia & 8 & 0 & 0 \\
\hline Biópsias & 13 & 0 & 0 \\
\hline Correção de codo & 2 & 0 & 0 \\
\hline Curativos & 3 & 0 & 0 \\
\hline Decorticação pulmonar & 4 & 0 & 0 \\
\hline Hérnia diafragmática & 1 & 1 & 100 \\
\hline Lobectomia (pneumatocele) & 6 & 2 & 33,33 \\
\hline Mediastinoscopia & 2 & 0 & 0 \\
\hline Ressecção de folheto & 1 & 0 & 0 \\
\hline Retirada de nódulo de pulmão & 3 & 0 & 0 \\
\hline Toracotomia exploradora & 31 & 11 & 35,48 \\
\hline Outros & 38 & 5 & 13,16 \\
\hline Total & 460 & 227 & 49,35 \\
\hline
\end{tabular}

* Dos 102 marcapassos implantados no ano do 1999, apenas quatro foram realizados com anestesia geral e inseridos no presente levantamento. 
Tabela 12 Procedimentos cirúrgicos realizados pelo Serviço de Cirurgia de Cabeça e Pescoço do HCFMRPUSP e incidência de transfusão sangüínea intra-operatória no ano de 1999.

\begin{tabular}{lccc}
\hline \multicolumn{1}{c}{ Procedimentos } & $\begin{array}{c}\text { Número de } \\
\text { Procedimentos }\end{array}$ & $\begin{array}{c}\text { Procedimentos } \\
\text { c/ } \\
\text { Transfusão }\end{array}$ & $\begin{array}{c}\text { \% de pacientes } \\
\text { transfundidos } \\
\text { p/procedimento }\end{array}$ \\
\hline Antrectomia & 4 & 0 & 0 \\
Biópsias & 7 & 0 & 0 \\
Estenose Traquéia ou Esôfago & 14 & 0 & 0 \\
Correção de fratura de malar & 1 & 0 & 0 \\
Correção de fratura mandíbula & 8 & 0 & 0 \\
Correção de prognatismo & 8 & 3 & 37,50 \\
Curetagem de mandíbula & 5 & 0 & 0 \\
Drenagem de abcessos & 3 & 0 & 0 \\
Esvaz.cervical + laringectom. & 13 & 5 & 38,46 \\
Exerese de cisto tireoglosso & 11 & 0 & 0 \\
Exerese de epiglote & 2 & 0 & 0 \\
Exerese de lesão nasal & 1 & 0 & 0 \\
Exerese de melanoma & 1 & 0 & 0 \\
Exerese de nódulos & 7 & 0 & 0 \\
Exerese de papilomas & 1 & 0 & 0 \\
Exerese de retalho & 1 & 0 & 0 \\
Exploração cervical & 11 & 1 & 9,09 \\
Fistulectomia & 16 & 1 & 6,25 \\
Hemiglossectomia & 1 & 0 & 0 \\
Tireoidectomia & 31 & 0 & 0 \\
Laringectomia total ou parcial & 44 & 10 & 22,73 \\
Mandibulectomia & 9 & 0 & 0 \\
Microcirurgia de laringe & 1 & 0 & 0 \\
Lefort II e III & 3 & 1 & 33,33 \\
Parotidectomia & 19 & 0 & 0 \\
Pull Throug (CA de língua) & 16 & 0 & 0 \\
Reconstrução cervical & 2 & 0 & 0 \\
Revisão de traqueostomia & 2 & 0 & 0 \\
Rinosseptoplastia & 8 & 0 & 0 \\
Traqueostomia & 10 & 0 & 0 \\
Amigdalectomia & 42 & 0 & 0 \\
Exérese Cisto branquial & 5 & 0 & 0 \\
Rot. Retalho soalho da boca & 1 & 1 & 0 \\
Outros & 26 & 0 & $\mathbf{0}$ Total \\
\hline & $\mathbf{3 3 4}$ & $\mathbf{2 2}$ & \\
\hline & & & \\
\hline & & 0 & 0 \\
\hline
\end{tabular}




\begin{tabular}{|c|c|c|c|}
\hline Tabela 13 & \multicolumn{3}{|c|}{$\begin{array}{l}\text { Procedimentos cirúrgicos realizados pelo Serviço de } \\
\text { Cirurgia Plástica do HCFMRPUSP e incidência de } \\
\text { transfusão sangüínea intra-operatória no ano de } 1999 .\end{array}$} \\
\hline Procedimentos & $\begin{array}{c}\text { Número de } \\
\text { Procedimentos }\end{array}$ & $\begin{array}{l}\text { Procedimentos c/ } \\
\text { Transfusão }\end{array}$ & $\begin{array}{l}\text { \% de Pacientes } \\
\text { transfundidos p/ } \\
\text { procedimento }\end{array}$ \\
\hline Blefaroplastia & 1 & 0 & 0 \\
\hline Correção de ginecomastia & 3 & 0 & 0 \\
\hline Curativos & 2 & 0 & 0 \\
\hline Dermolipectomia & 6 & 0 & 0 \\
\hline Desbridamentos & 1 & 0 & 0 \\
\hline Desbridamentos + enxertos & 8 & 0 & 0 \\
\hline Exerese de hemangioma & 2 & 0 & 0 \\
\hline Exerese de malanoma & 20 & 0 & 0 \\
\hline Enxertos & 11 & 1 & 9,09 \\
\hline Exerese de lipoma & 2 & 0 & 0 \\
\hline Exerese de neurofibromat. & 1 & 0 & 0 \\
\hline Esvaziamento axilar & 4 & 0 & 0 \\
\hline Exerese de cistos & 2 & 0 & 0 \\
\hline Lipoaspiração & 11 & 0 & 0 \\
\hline Mastopexia bilateral & 2 & 0 & 0 \\
\hline Mastoplastia & 33 & 0 & 0 \\
\hline Otoplastia & 4 & 0 & 0 \\
\hline Palatoplastia & 1 & 0 & 0 \\
\hline Ritidectomia & 2 & 0 & 0 \\
\hline Rinoplastia & 20 & 0 & 0 \\
\hline Prótese expansora & 1 & 0 & 0 \\
\hline Biópsias & 1 & 0 & 0 \\
\hline Cor. Lábio leporino & 1 & 0 & 0 \\
\hline Rotação de retalho cutâneo & 2 & 2 & 100 \\
\hline Outros & 28 & 0 & 0 \\
\hline Reconstrução de mama & 4 & 1 & 25,00 \\
\hline Total & 173 & 4 & 2,31 \\
\hline
\end{tabular}

A distribuição, quanto à faixa etária, dos pacientes transfundidos encontra-se na tabela 14. 


\begin{tabular}{lccc} 
Tabela 14 & \multicolumn{4}{c}{$\begin{array}{l}\text { Pacientes transfundidos no período intra-operatório no } \\
\text { HCFMRPUSP } \\
\text { diferentes faixas etárias. }\end{array}$} & $\begin{array}{c}\text { 1999, } \\
\text { distribuídos }\end{array}$ \\
\hline \multicolumn{1}{c}{ Faixa } & $\begin{array}{c}\text { População } \\
\text { etária }\end{array}$ & $\begin{array}{c}\text { População } \\
\text { Transfundida }\end{array}$ & $\begin{array}{c}\text { \% de pacientes } \\
\text { transfundidos }\end{array}$ \\
\hline Rn & 109 & 28 & 25,68 \\
Lactente & 269 & 14 & 5,20 \\
Criança & 1709 & 64 & 3,74 \\
Adulto & 7344 & 484 & 6,59 \\
Geriátrico & 1487 & 219 & 14,72 \\
\hline Total & $\mathbf{1 0 9 1 8}$ & $\mathbf{8 0 9}$ & $\mathbf{7 , 4 0}$ \\
\hline
\end{tabular}

Os resultados da Tabela 14 estão representados, graficamente, nas figuras 5, 6 e 7 .
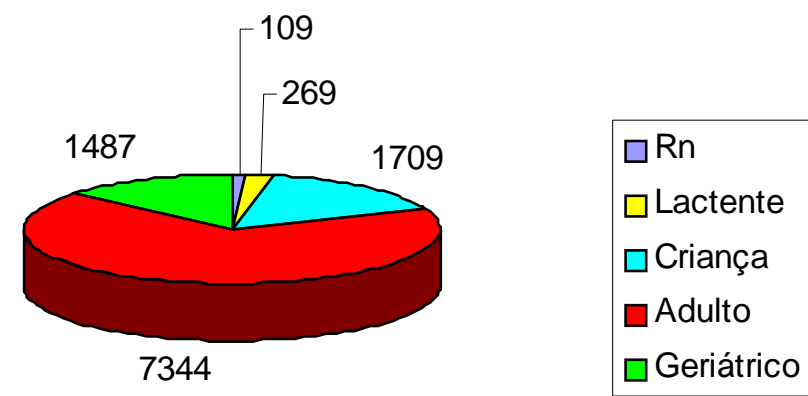

Total de Cirurgias

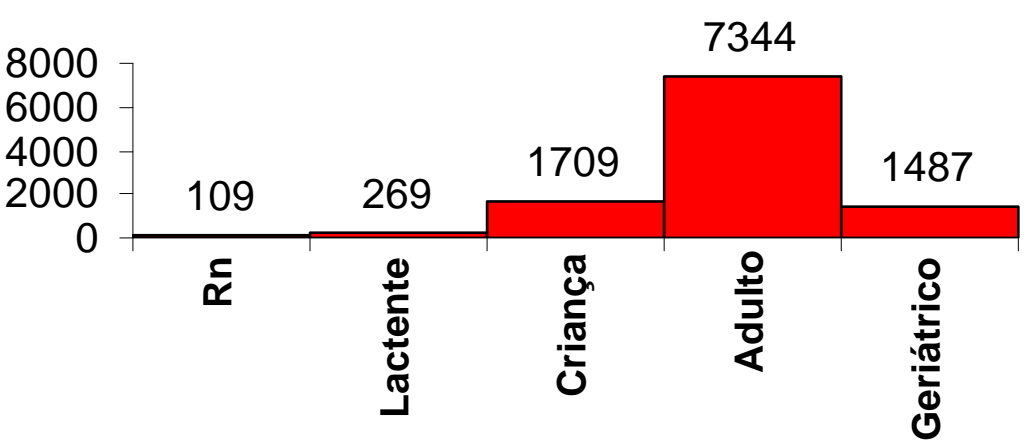

Fig. 5 Número de pacientes, por faixa etária, que se submeteram a procedimento cirúrgico ou diagnóstico sob anestesia no ano de 1999, no HCFMRPUSP. 


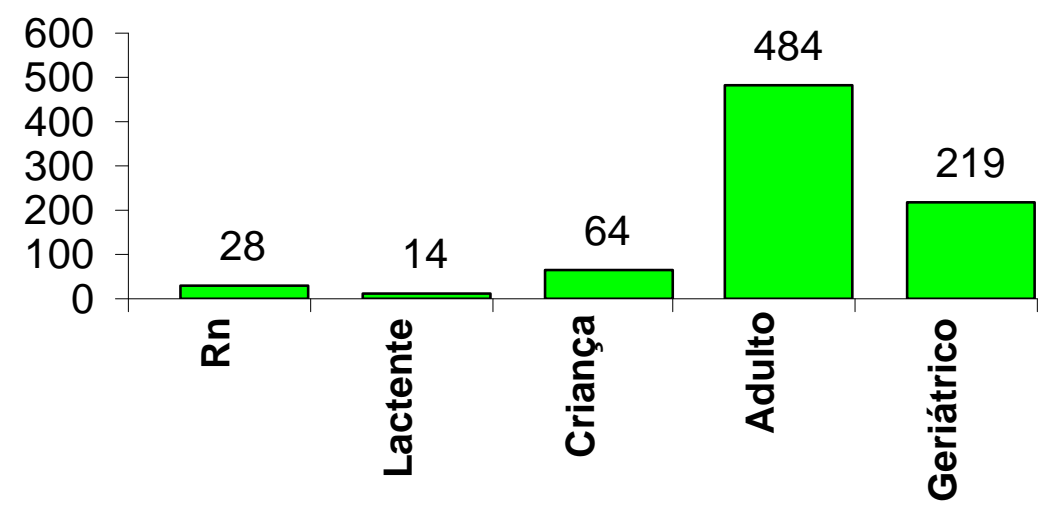

Fig. 6 Número de pacientes, por faixa etária, que receberam hemoderivado e/ou componente sanguíneo, durante o período intra-operatório, durante o ano de 1999 no HCFMRPUSP.

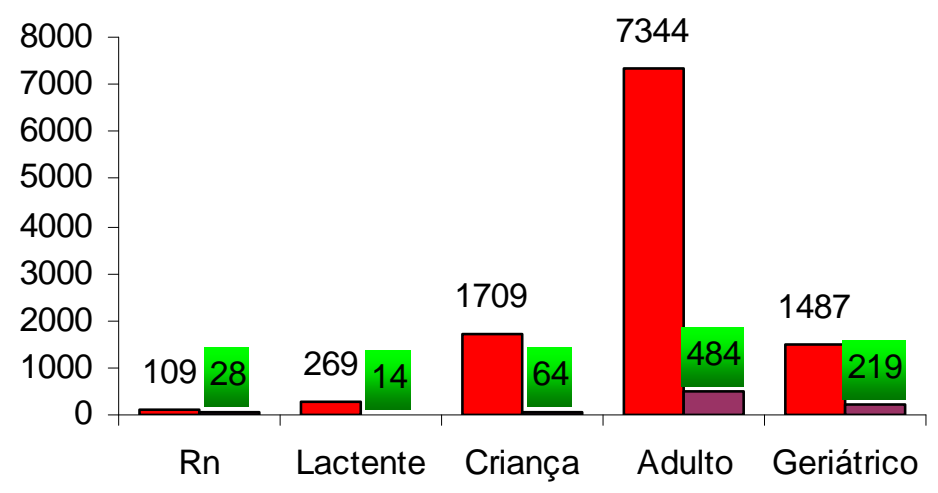

Fig. 7 Número de anestesias por faixa etária e número de pacientes que receberam hemoderivado e/ou componente sangüíneo durante o período intra-operatório, no ano de 1999 no HCFMRPUSP. 
A distribuição dos pacientes que receberam hemoderivado ou componente sangüíneo, em cada mês e em procedimentos eletivos ou de urgência, pode ser vista nas tabelas 15, 16 e 17. Do total de procedimentos anestésicos realizados, 8832 deles foram em regime eletivo e 2086 em regime de urgência.

\begin{tabular}{|c|c|c|c|}
\hline Tabela 15 & \multicolumn{3}{|c|}{$\begin{array}{l}\text { Porcentagem de pacientes transfundidos no período intra-operatório no } \\
\text { HCFMRPUSP no ano de 1999. Distribuição mensal. }\end{array}$} \\
\hline Mês & $\begin{array}{c}\mathrm{N}^{0} \text { total } \\
\text { de cirurgias }\end{array}$ & $\begin{array}{c}\text { Cirurgias com } \\
\text { transfusão }\end{array}$ & $\begin{array}{l}\text { \% de pacientes } \\
\text { transfundidos }\end{array}$ \\
\hline Janeiro & 751 & 67 & 8.92 \\
\hline Fevereiro & 681 & 56 & 8.22 \\
\hline Março & 958 & 81 & 8.45 \\
\hline Abril & 920 & 73 & 7.93 \\
\hline Maio & 881 & 73 & 8.28 \\
\hline Junho & 1027 & 52 & 5.06 \\
\hline Julho & 1147 & 61 & 5.31 \\
\hline Agosto & 1044 & 68 & 6.51 \\
\hline Setembro & 882 & 64 & 7.25 \\
\hline Outubro & 860 & 69 & 8.02 \\
\hline Novembro & 915 & 65 & 7.10 \\
\hline Dezembro & 852 & 80 & 9.38 \\
\hline Total 1999 & 10918 & 809 & 7.40 \\
\hline
\end{tabular}

Tabela 16 Utilização de componentes e derivados sangǘneos no período intraoperatório, em cirurgias eletivas no HCFMRPUSP no ano de 1999. Distribuição mensal.

\begin{tabular}{|c|c|c|c|}
\hline Mês & $\begin{array}{l}\mathrm{N}^{0} \text { total de } \\
\text { cirurgias }\end{array}$ & $\begin{array}{c}\text { Cirurgias com } \\
\text { transfusão }\end{array}$ & $\begin{array}{l}\text { \% de pacientes } \\
\text { transfundidos }\end{array}$ \\
\hline Janeiro & 587 & 55 & 9,37 \\
\hline Fevereiro & 526 & 41 & 7,79 \\
\hline Março & 759 & 70 & 9,22 \\
\hline Abril & 702 & 59 & 8,40 \\
\hline Maio & 684 & 65 & 9,50 \\
\hline Junho & 860 & 44 & 5,11 \\
\hline Julho & 972 & 49 & 5,04 \\
\hline Agosto & 874 & 51 & 5,83 \\
\hline Setembro & 719 & 51 & 7,09 \\
\hline Outubro & 685 & 53 & 7,73 \\
\hline Novembro & 781 & 56 & 7,17 \\
\hline Dezembro & 674 & 60 & 8,90 \\
\hline Total 1999 & 8832 & 654 & 7,40 \\
\hline
\end{tabular}


Tabela 17 Utilização de componentes e derivados sangüíneos no período intraoperatório, em cirurgias de urgência no HCFMRPUSP no ano de 1999. Distribuição mensal.

\begin{tabular}{lccc}
\hline \multicolumn{1}{c}{ Mês } & $\begin{array}{c}\text { Cirurgias de } \\
\text { Urgência }\end{array}$ & $\begin{array}{c}\text { Cirurgias de Urgência } \\
\text { / / transfusão }\end{array}$ & $\begin{array}{c}\text { \% de pacientes } \\
\text { transfundidos }\end{array}$ \\
\hline Janeiro & 173 & 12 & 6,93 \\
Fevereiro & 155 & 15 & 9,67 \\
Março & 199 & 11 & 5,52 \\
Abril & 218 & 14 & 6,42 \\
Maio & 197 & 8 & 4,06 \\
Junho & 167 & 8 & 4,79 \\
Julho & 175 & 12 & 6,85 \\
Agosto & 170 & 17 & 10,0 \\
Setembro & 163 & 13 & 7,97 \\
Outubro & 155 & 16 & 10,32 \\
Novembro & 135 & 10 & 7,40 \\
Dezembro & 178 & 19 & 10,67 \\
\hline \multicolumn{1}{c}{ Total } & $\mathbf{2 0 8 6}$ & $\mathbf{1 5 5}$ & $\mathbf{7 , 4 3}$ \\
\hline
\end{tabular}

A relação entre o tempo de procedimento anestésico-cirúrgico e a freqüência de utilização de hemoderivado e/ ou componente sangüíneo pode ser vista na Tabela 18.

\begin{tabular}{cccc} 
Tabela 18 & $\begin{array}{l}\text { Tempo anestésico-cirúrgico } \\
\text { sangǘnea no período intra-operatório no } \\
\text { ano de 1999. }\end{array}$ & \multicolumn{3}{c}{ e } & frequência & $\begin{array}{c}\text { de } \\
\text { transfusão }\end{array}$ \\
\hline $\begin{array}{c}\text { Intervalo de } \\
\text { duração da anestesia }\end{array}$ & População & $\begin{array}{c}\text { População } \\
\text { Transfundida }\end{array}$ & $\begin{array}{c}\text { \% de pacientes } \\
\text { transfundidos }\end{array}$ \\
\hline Até 60 minutos & 2029 & 24 & 1,18 \\
60 a 120 minutos & 3924 & 100 & 2,54 \\
121 a 180 minutos & 2261 & 136 & 6,01 \\
181 a 240 minutos & 1129 & 178 & 15,76 \\
241 a 300 minutos & 752 & 143 & 19,00 \\
301 a 360 minutos & 365 & 85 & 23,28 \\
361 a 420 minutos & 222 & 75 & 33,78 \\
421 a 480 minutos & 116 & 30 & 25,86 \\
481 a 540 minutos & 61 & 20 & 32,78 \\
541 a 600 minutos & 30 & 12 & 40,00 \\
601 a 660 minutos & 14 & 3 & 21,42 \\
661 a 720 minutos & 9 & 1 & 11,11 \\
721 a 780 minutos & 4 & 1 & 25,00 \\
781 a 900 minutos & 2 & 1 & 50,00 \\
\hline Total & $\mathbf{1 0 9 1 8}$ & $\mathbf{8 0 9}$ & $\mathbf{7 , 4 0}$ \\
\hline
\end{tabular}


A incidência de transfusão sangüínea em cada tipo de anestesia está assinalada na tabela 19.

Tabela 19 Técnica anestésica empregada e freqüência de transfusão sangüínea no período intra-operatório no HCFMRPUSP no ano de 1999.

\begin{tabular}{lccc}
\hline $\begin{array}{c}\text { Tipo de } \\
\text { Anestesia }\end{array}$ & População geral & $\begin{array}{c}\text { População } \\
\text { transfundida }\end{array}$ & $\begin{array}{c}\text { \% de pacientes } \\
\text { transfundidos }\end{array}$ \\
\hline Raqui & 2830 & 37 & 1,30 \\
Peri & 843 & 15 & 1,78 \\
Geral & 6126 & 596 & 9,73 \\
Combinada & 295 & 161 & 54,57 \\
Bloqueio & 813 & 0 & 0 \\
Local & 12 & 0 & 0 \\
\hline \multicolumn{1}{r}{ Total } & $\mathbf{1 0 9 1 8}$ & $\mathbf{8 0 9}$ & $\mathbf{7 , 4 0}$ \\
\hline
\end{tabular}

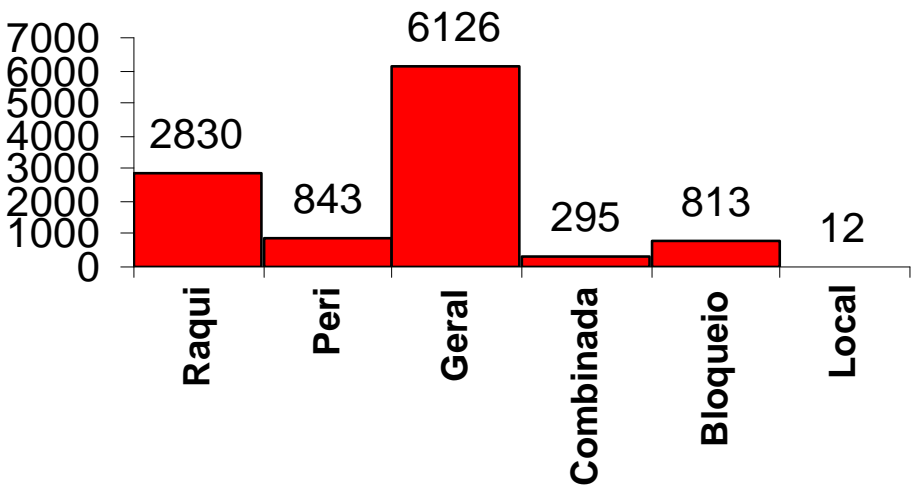

Fig. 8 Técnica anestésica empregada em 10918 procedimentos cirúrgicos ou diagnósticos no ano de 1999, no HCFMRPUSP 


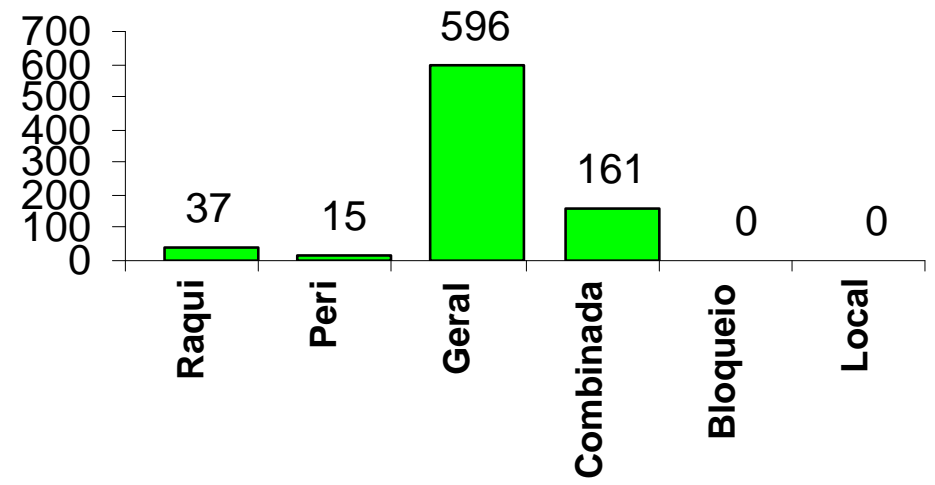

Fig. 9 Número de pacientes que receberam hemoderivado ou componente sangüíneo em cada técnica anestésica empregada para a realização de 10918 procedimentos cirúrgicos ou diagnósticos no ano de 1999, no HCFMRPUSP

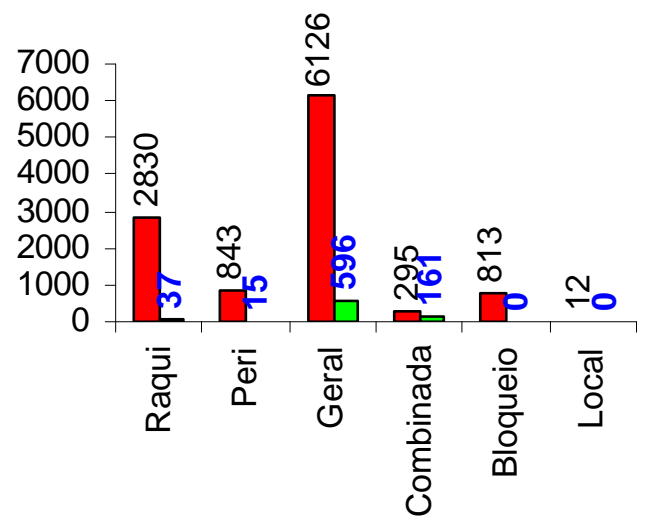

$\square$ Número de procedimentos

$\square$ Pacientes transfundidos

Fig. 10 Número de procedimentos realizados com cada técnica anestésica e número de pacientes que receberam hemoderivado ou componente sangüíneo em cada técnica anestésica empregada para a realização de 10918 procedimentos cirúrgicos ou diagnósticos no ano de 1999, no HCFMRPUSP. 
Muitos dos pacientes foram transfundidos tendo como critério de indicação da transfusão apenas os parâmetros clínicos. Dos 809 pacientes que receberam algum tipo de componente sangüíneo durante o período intra-operatório, 484 deles tiveram a hemoglobina quantificada antes da transfusão e 510 o hematócrito aferido. Apenas 24 pacientes tiveram a quantificação do número de plaquetas antes da transfusão. Nas demais fichas anestésicas não foi possível saber se foram realizados exames laboratoriais antes da transfusão ou se o anestesiologista deixou de constar no relatório de anestesia. Nas tabelas 20, 21 e 22 estão demonstrados, respectivamente, os valores pré transfusionais da hemoglobina, do hematócrito e das plaquetas.

\begin{tabular}{ccc} 
Tabela 20 & $\begin{array}{l}\text { Hemoglobina medida no exame pré-operatório ou } \\
\text { intraoperatório de pacientes } \\
\text { período intra-operatório no } \\
\text { 1999. }\end{array}$ & $\begin{array}{c}\text { oubmetidos a transfusão no } \\
\text { HCFRPUSP, no ano de }\end{array}$ \\
\hline $\begin{array}{c}\text { Taxa de hemoglobina } \\
\text { (g/100ml) }\end{array}$ & $\begin{array}{c}\text { Número de } \\
\text { pacientes }\end{array}$ & $\begin{array}{c}\text { \% de } \\
\text { pacientes }\end{array}$ \\
\hline$<5$ & 3 & 0,37 \\
5,0 a 9,0 & 173 & 21,38 \\
9,0 a 10 & 139 & 17,18 \\
> 10 & 169 & 20,88 \\
Não quantificada & 325 & 40,17 \\
\hline TOTAL & $\mathbf{8 0 9}$ & $\mathbf{1 0 0}$ \\
\hline
\end{tabular}

\begin{tabular}{ccc} 
Tabela 21 & $\begin{array}{l}\text { Hematócrito medido no exame pré-operatório ou } \\
\text { intraoperatório de pacientes } \\
\text { período intra-operatório no } \\
\text { 1999. }\end{array}$ & $\begin{array}{c}\text { oubmetidos a transfusão no } \\
\text { HCFRPUSP, }\end{array}$ \\
no ano de \\
Hematócrito & $\begin{array}{c}\text { Número de } \\
\text { pacientes }\end{array}$ & $\begin{array}{c}\text { \% de } \\
\text { pacientes }\end{array}$ \\
\% & 286 & 35,35 \\
\hline$<30$ & 203 & 25,09 \\
30 a 40 & 20 & 2,47 \\
40 a 50 & 1 & 0,12 \\
$>50$ & 299 & 36,95 \\
\hline Não quantificada & $\mathbf{8 0 9}$ & $\mathbf{1 0 0}$ \\
\hline TOTAL & &
\end{tabular}




\begin{tabular}{|c|c|c|c|}
\hline Tabela 22 & \multicolumn{3}{|c|}{$\begin{array}{l}\text { Número de plaquetas medido no exame pré-operatório ot } \\
\text { intraoperatório de pacientes submetidos a transfusão ne } \\
\text { período intra-operatório no HCFMRPUSP, no ano de } \\
1999 .\end{array}$} \\
\hline \multicolumn{2}{|c|}{$\begin{array}{c}\text { Número de Plaquetas } \\
\text { (plaquetas/ml) }\end{array}$} & $\begin{array}{l}\text { Número de } \\
\text { pacientes }\end{array}$ & $\begin{array}{c}\% \text { de } \\
\text { pacientes }\end{array}$ \\
\hline \multicolumn{2}{|c|}{$<50.000$} & 3 & 0,37 \\
\hline \multicolumn{2}{|c|}{50.000 a 100.000} & 1 & 0,12 \\
\hline \multicolumn{2}{|c|}{100.000 a 140.000} & 2 & 0,24 \\
\hline \multicolumn{2}{|c|}{140.000 a 400.000} & 10 & 1,23 \\
\hline \multicolumn{2}{|c|}{$>400.000$} & 8 & 0,98 \\
\hline \multicolumn{2}{|c|}{ Não quantificada } & 785 & 97,03 \\
\hline \multicolumn{2}{|c|}{ TOTAL } & 809 & 100 \\
\hline
\end{tabular}

Os resultados desses exames realizados estão

expressos na tabela 23.

\begin{tabular}{|c|c|c|c|c|}
\hline Tabela 23 & \multicolumn{4}{|c|}{$\begin{array}{l}\text { Resultados dos exames pré-transfusão colhidos de pacientes } \\
\text { submetidos a transfusão sangüínea intra-operatória no } \\
\text { HCFMRPUSP, no ano de } 1999 \text {. }\end{array}$} \\
\hline Parâmetro & $\begin{array}{c}\mathbf{N}^{0} \text { de } \\
\text { Pacientes }\end{array}$ & $\begin{array}{c}\text { Média } \\
\text { (desvio padrão) }\end{array}$ & Variação & $\begin{array}{c}\text { Valores } \\
\text { Normais }\end{array}$ \\
\hline $\begin{array}{l}\text { Hemoglobina } \\
\text { g/dl }\end{array}$ & 484 & $\begin{array}{c}9,53 \\
(2,13)\end{array}$ & 4,8 a 20 & $\begin{array}{l}\text { F } 11,7 \text { a } 15,7 \\
\text { M } 13,3 \text { a } 17,7\end{array}$ \\
\hline $\begin{array}{c}\text { Hematócrito } \\
\%\end{array}$ & 510 & $\begin{array}{l}28,69 \\
(6,59)\end{array}$ & 14 a 59 & $\begin{array}{l}\text { F } 35 \text { a } 47 \% \\
\text { M } 40 \text { a } 52 \%\end{array}$ \\
\hline $\begin{array}{l}\text { Plaquetas } \\
\text { (mil/ml) }\end{array}$ & 24 & $\begin{array}{c}56,166 \\
(21,937)\end{array}$ & 20 a 95 & 140 a 400 \\
\hline
\end{tabular}

A quantidade média de cada componente sangüíneo que foi infundida nos pacientes está demonstrada na tabela 24 . 


\begin{tabular}{|c|c|c|c|}
\hline $\begin{array}{l}\text { Componente } \\
\text { Infundido }\end{array}$ & $\begin{array}{c}\text { Total de } \\
\text { Pacientes } \\
\end{array}$ & $\%$ & $\begin{array}{l}\text { Quantidade Infundida (ml) } \\
\text { Média (desvio padrão) }\end{array}$ \\
\hline Albumina 5\% & 90 & 11,12 & $\begin{array}{c}140,31 \mathrm{ml} \\
(229,65)\end{array}$ \\
\hline $\begin{array}{l}\text { Papa de } \\
\text { hemácias }\end{array}$ & 644 & 79,60 & $\begin{array}{c}662,85 \mathrm{ml} \\
(540,27)\end{array}$ \\
\hline Plasma & 393 & 48,57 & $\begin{array}{c}505,88 \mathrm{ml} \\
(359,93)\end{array}$ \\
\hline Crioprecipitado & 12 & 1,48 & $\begin{array}{c}309,58 \mathrm{ml} \\
(272,26)\end{array}$ \\
\hline Sangue Total & 69 & 8,52 & $\begin{array}{l}734,82 \mathrm{ml} \\
(1042,82)\end{array}$ \\
\hline Plaquetas & 82 & 10,13 & $\begin{array}{c}484,63 \mathrm{ml} \\
(555,93)\end{array}$ \\
\hline $\begin{array}{c}\text { Colóides } \\
\text { Cristalóides }\end{array}$ & 809 & 100,0 & $\begin{array}{c}2349,27 \mathrm{ml} \\
(1706,89)\end{array}$ \\
\hline
\end{tabular}

Tabela 25 Número de pacientes que recebeu papa de hemácias e/ou plasma e volume desses componentes que foi infundido no período intra-operatório, no HCFMRPUSP, em 1999.

\begin{tabular}{ccc}
\hline $\begin{array}{c}\text { Volume } \\
\text { Infundido(ml) }\end{array}$ & $\begin{array}{c}\text { Papa de Hémácias } \\
\text { Número de pacientes }\end{array}$ & $\begin{array}{c}\text { Plasma } \\
\text { Número de pacientes }\end{array}$ \\
\hline$<150$ & 44 & 24 \\
151 - 300s & 86 & 88 \\
301 a 500 & 192 & 162 \\
501 a 800 & 160 & 66 \\
801 a 1200 & 83 & 36 \\
1201 a 1500 & 36 & 6 \\
1501 a 2000 & 23 & 8 \\
2001 a 2700 & 15 & 2 \\
2701 a 3000 & 0 & 1 \\
$>3000$ & 5 & 0 \\
\hline Total & $\mathbf{6 4 4}$ & $\mathbf{3 9 3}$ \\
\hline
\end{tabular}




\begin{tabular}{|c|c|}
\hline $\begin{array}{l}\text { Quantidade de pacient } \\
\text { componente sangüíneo } \\
\text { período intra-operatório } \\
\text { de } 1999 \text {. }\end{array}$ & $\begin{array}{l}\text { recebeu cada tipo de } \\
\text { emoderivado durante o } \\
\text { MRPUSP durante o ano }\end{array}$ \\
\hline Hemoderivado & Número de Pacientes \\
\hline Exclusivamente papa de hemácias & 274 \\
\hline Exclusivamente plasma & 47 \\
\hline Exclusivamente plaquetas & 15 \\
\hline Exclusivamente crioprecipitado & 0 \\
\hline Exclusivamente sangue total & 36 \\
\hline Papa de hemácias + plasma & 260 \\
\hline Papa de hemácias + plasma + plaquetas & 28 \\
\hline Papa de hemácias + plasma + albumina & 15 \\
\hline Papa + plasma + albumina + plaquetas & 3 \\
\hline $\begin{array}{l}\text { Papa }+ \text { plasma }+ \text { albumina }+ \text { plaquetas }+ \\
\text { crioprecipitado }\end{array}$ & 4 \\
\hline Sangue total + papa & 7 \\
\hline Sangue total + plasma & 12 \\
\hline
\end{tabular}

\section{Complicações}

Apenas uma complicação ficou claramente demonstrada ter ocorrido pela transfusão sanguínea, que foi o aparecimento de pápulas após a transfusão de plaquetas, que se solucionou com facilidade após a interrupção da transfusão. 


\section{DISCUSSÃO}




\section{5 - DISCUSSÃO}

A prática de transfundir componentes sangüíneos traz benefícios significativos aos pacientes podendo, inclusive, livrá-los da morte. Entretanto a possibilidade de transmissão de doenças infecciosas, que têm muitas vezes uma janela sorológica e não têm cura como a Aids, torna a indicação de uma transfusão homóloga mais criteriosa, onde os benefícios devem ser maiores que os riscos (VANE \& CASTIGLIA, 2000).

Apesar do conhecimento sobre os riscos da transfusão sangǘnea ser antigo, após o aparecimento da Síndrome da Imunodeficiência Adquirida a preocupação com o problema aumentou. Tem havido um interesse crescente em se discutir, sempre, a relação risco/benefício de cada transfusão. Mesmo assim, existem vários estudos sugerindo que o uso de sangue e de seus componentes é excessivo (McCULLOUGH et al, 1988; MATHOULIN-PELISSIER et al, 2000). Com o intuito de reduzir as transfusões desnecessárias, auditorias têm sido realizadas. Essas auditorias analisam, prospectivamente ou retrospectivamente, a prática transfusional de um determinado local e propõem medidas, dentro da prática considerada padrão, para otimizar o uso do sangue e de seus derivados. A análise retrospectiva é difícil de ser realizada, pois nem sempre os dados retirados dos prontuários dos pacientes podem ser confiáveis. Por outro lado, a análise prospectiva também apresenta dificuldades, já que o preenchimento de formulários pode atrasar uma transfusão necessária. Além disso, o hematócrito, um dos critérios utilizados para se avaliar a necessidade de transfusão, não traduz, com acurácia, o volume eritrocitário no paciente que está sangrando profusamente. Devido às dificuldades para se realizar uma auditoria prospectiva, esse estudo foi realizado por meio de auditoria retrospectiva. Como o intuito foi avaliar a prática de um grupo de médicos, no caso os anestesiologistas, o estudo se restringiu ao período intra-operatório. Embora o período intraoperatório represente apenas uma fração do tempo que o paciente cirúrgico permanece no hospital, é esse o único período que a indicação da transfusão é de responsabilidade exclusiva do anestesiologista, já que nos períodos pré-operatório e pós-operatório a indicação possa também ser feita pelos cirurgiões. Esse estudo não teve o objetivo de encontrar erros de indicação e nem confrontar a prática transfusional do Serviço de Anestesiologia do Hospital das Clínicas de Ribeirão Preto com a prática considerada padrão. 
O anestesiologista responde por cerca de $60 \%$ das transfusões realizadas (VANE \& CASTIGLIA, 2000). Ele usa como subsídios para a sua indicação a perda sanguínea, os exames laboratoriais e as manifestações clínicas.

A principal função do sangue é a oxigenação tecidual, carreando o oxigênio dos pulmões aos tecidos. Essa função é exercida pelas células vermelhas presentes no concentrado de hemácias e no sangue total. Algumas outras substâncias foram sintetizadas na tentativa de substituir as células vermelhas nessa função, tal como a emulsão de perfluorocarbono (REMY et al., 1999), que tem a vantagem de não necessitar de teste de compatibilidade para ser utilizada e as desvantagens de não possuir a mesma eficácia e predispor o paciente ao aparecimento de coagulopatias.(HESS., 1996).

Os dados apresentados neste estudo não foram submetidos a tratamento estatístico, já que toda a população submetida à anestesia no ano de 1999 foi incluída. Dessa forma, todos os dados foram apresentados na forma de porcentual. Pretendia-se, no início, avaliar condutas individuais dos anestesiologistas e o sangramento existente em cada procedimento cirúrgico, por cirurgião. Na organização dos resultados, verificou-se que isso seria impossível, pois o número de tipos de procedimentos cirúrgicos é enorme e o número de cirurgiões pequeno. Além disso, existe um rodízio muito grande entre os anestesiologistas na realização da maioria dos atos anestésicos e pouco rodízio na realização de atos anestésicos para procedimentos cirúrgicos específicos como cirurgia cardíaca, neurocirurgia e cirurgia ginecológica. Assim, optou-se por fazer uma análise global da prática transfusional.

A incidência de transfusão sangüínea varia de um centro para outro. No Hospital das Clínicas de Ribeirão Preto, ela ocorreu em 809 (7,40\%) dos 10918 procedimentos anestésicos realizados no ano de 1999. Embora não se tenha conseguido diferenciar os tipos de técnica transfusional, a grande maioria (quase a totalidade) dessas transfusões foram homólogas. A transfusão autóloga, apesar de incentivada, ainda tem utilização reduzida entre os pacientes cirúrgicos no nosso hospital, mas foi utilizada largamente nos pacientes doadores de medula óssea (8 pacientes em 18, 44,44\%). A disciplina com maior incidência de pacientes transfundidos foi a de Cirurgia Torácica, com 49,34\%. Nesta especialidade, muitas vezes utiliza-se concentrado de hemácias já no perfusato da circulação extra corpórea, procedimento que provoca hemólise e consumo de 
fatores de coagulação, o que implica na necessidade de reposição desses componentes. Considerando que os procedimentos realizados são sobre o coração e os pulmões, esta taxa está dentro do usual. A freqüência de transfusão em cirurgias para revascularização do miocárdio foi de 69,29\%. Em um estudo que incluiu 24 centros de cirurgia cardíaca, a taxa de pacientes transfundidos em revascularização do miocárdio variou de 27 a 92\% (PRICE STOVER et al, 1998). Na Comunidade Européia, para o mesmo tipo de cirurgia, variou de 17,1 a 100\% (SIRCHI et al, 1994). Nos Estados Unidos, a proporção de pacientes cirúrgicos transfundidos vem diminuindo desde o início da década de 90 e o número médio de unidades de glóbulos vermelhos transfundidas para cada paciente vem crescendo regularmente. Isso sugere que, cada vez mais, a transfusão está reservada para os pacientes que sangram muito (VAMVAKAS, 1996). Ainda nos Estados Unidos, 20\% do total de transfusões acontecem durante cirurgias ortopédicas, 15\% durante cirurgias cardíacas ou vasculares, 5,8\% durante cirurgias gastrintestinais e 2,8\% durante cirurgias urológicas (VAMVAKAS \& TASWELL, 1994). Na França, também é a cirurgia ortopédica que se coloca em primeiro lugar no tocante à incidência de transfusão sangüínea. Neste país, os procedimentos ortopédicos são responsáveis por $48 \%$ das transfusões e compreendem apenas $26 \%$ do total de cirurgias realizadas (LIEHART et al, 1998). Aqui, a Ortopedia é responsável por 10,82\% do total de procedimentos e 7,02\% das transfusões realizadas. Nossa taxa de transfusão em cirurgia ortopédica é aparentemente menor do que as demonstradas pelos estudos americano e francês e isso talvez possa ser explicado pelo alto número de cirurgias com a utilização do garrote e pelo alto número de cirurgias de mão. Em cirurgia de quadril, temos, de fato, uma taxa reduzida de transfusão (28\%), em contraste com o que ocorre na Comunidade Européia (29,3 a $100 \%)$.

A especialidade Ginecologia \& Obstetrícia realiza diversos tipos de cirurgia. A taxa global de transfusão (3,36\%) é baixa, embora em alguns tipos, como no Werthein-Meigs, chegue a 76\%. Em histerectomia, a taxa de transfusão é de $6,5 \%$ e em cesariana, de $9,4 \%$. O conhecimento desses números nos permite prever quais cirurgias necessitam de reserva de sangue e quais seria possível realizar sem essa reserva. De 118 mastoplastias ou mastectomias realizadas em 1999, em nenhumas delas foi necessária a transfusão. 
Em alguns procedimentos cirúrgicos, a transfusão sangüínea é quase obrigatória. De 21 aneurismectomias abdominais, a transfusão ocorreu em todas; de 14 hepatectomias, houve transfusão em 13 (92,85\%). Aconteceu, também, 19 vezes em 45 nefrectomias, 19 vezes em 35 prostatectomias e 18 vezes em 58 implantes renais. Entretanto em procedimentos oftalmológicos, é quase sempre exceção. Nas 965 cirurgias realizadas, só aconteceu duas vezes, mesmo assim em cirurgias sobre a região da órbita e não sobre o olho propriamente dito.Da mesma forma, a incidência foi baixa em cirurgia otorrinolaringológica. Não ocorreu nenhuma vez em 102 amigdalectomias, cirurgia que mais amedronta o cirurgião e o anestesiologista no que se refere à perda sanguínea.

Em neurocirurgia, os procedimentos que mais requisitaram transfusão foram as clipagens de aneurisma e as craniotomias para exérese de tumor (32,14 e 35,84\%, respectivamente).

Na Disciplina de Cirurgia Plástica e Reparadora, somente 4 pacientes receberam transfusão em 173 procedimentos realizados. Fato interessante da nossa casuística foi a baixa incidência de transfusão em Cirurgia de Cabeça e Pescoço. Onde se esperava uma freqüência maior, pois os procedimentos são, em geral, oncológicos e de longa duração.

A casuística de 10918 procedimentos anestésicocirúrgicos é significativa para demonstrar a demanda de sangue no período intra-operatório, já que o Hospital das Clínicas de Ribeirão Preto é um hospital terciário e nele são realizados os mais diversos tipos de cirurgia. Tivemos a oportunidade de observar que em alguns tipos de cirurgia, a freqüência de transfusão foi zero, como aconteceu nas herniorrafias, nas cirurgias para correção da incontinência urinária e nas hemorroidectomias. Por outro lado, em cirurgias ortopédicas sobre a coluna, a incidência foi de 26,72\%, incluindo nesta série todos os tipos de procedimentos, desde uma simples laminectomia até as amplas artrodeses de coluna por via anterior e posterior. Com certeza, neste último tipo de procedimento isolado, a incidência de transfusão deve girar em torno de 100\%.

No que concerne à faixa etária, a grande maioria dos pacientes eram adultos (67,26\%), mas a porcentagem maior de pacientes transfundidos esteve concentrada nas faixas etárias extremas, ou seja, os recém-nascidos (25,68\%) e os geriátricos (14,72\%). Quando um recém-nascido necessita ser submetido a algum 
procedimento cirúrgico, em geral este procedimento é sobre o coração, daí o alto índice de transfusão nesta faixa etária. Dos 28 recém-nascidos que foram transfundidos, 9 foram submetidos à cirurgia de Blalock. Em idosos, a frequiência maior é de cirurgia ortopédica ou oncológica.

Nestas faixas etárias também é mais difícil avaliar, clinicamente, a necessidade de transfusão, o que acarreta maior quantidade de indicações equivocadas ou desnecessárias. Neles, a perda de pequenas quantidades de sangue, no intraoperatório, tem grande importância e pode trazer implicações clínicas mais danosas. Do nascimento até aproximadamente três anos de idade o parênquima medular dos ossos é a medula vermelha, considerada funcionante. Com o passar do tempo, ela é substituída pela medula amarela, considerada não funcionante, mas que pode funcionar sob determinadas circunstâncias. Finalmente ocorre a transformação da medula amarela em medula senil (cinza), considerada não funcionante. Dessa forma, a atividade hematopoiética do indivíduo idoso é mais frágil e sua reatividade diminui. Isso pode explicar a utilização de derivados sangüíneos no trans-operatório de pacientes geriátricos ser de 14,72\%.

A distribuição mensal das transfusões foi semelhante. Seria de se esperar um decréscimo nesta taxa, conforme o ano avança, levandose em conta que o Hospital das Clínicas é um hospital de ensino e que a prática melhore com o tempo. Cirurgia bem feita implica em menor sangramento e por consegüinte, em menor taxa de transfusão. Da mesma maneira, anestesiologista mais experiente convive melhor com as adversidades e pode tolerar mais a instabilidade circulatória antes de indicar uma transfusão. Também ocorre que os procedimentos de maior risco para sangramento são feitos, sempre, pelos cirurgiões mais experientes e isso pode explicar a distribuição mensal constante das transfusões. Da mesma forma, como a indicação da transfusão intra-operatória pertence ao anestesiologista, é possível que a decisão seja tomada, na maioria das vezes, pelo supervisor e não pelo médico em treinamento.

Dos 8832 procedimentos realizados em regime eletivo, houve transfusão sangüínea em 654 (7,40\%). A taxa foi a mesma nos 2086 procedimentos realizados em regime de urgência. A distribuição mensal foi semelhante nos dois regimes. Isso pode ser explicado pelo perfil dos procedimentos de urgência realizados no Hospital das Clínicas - Campus, que é um hospital que não atende pacientes vítimas de 
trauma. Dessa forma, os procedimentos realizados em regime de urgência são muito semelhantes aos do regime eletivo.

$$
\text { Intuitivamente, cirurgias com maior duração }
$$
apresentam maior sangramento do que aquelas de menor duração. A duração de um procedimento está relacionada à sua complexidade e em geral, quanto mais complexo um procedimento, maior possibilidade de sangramento ele apresentará. Existem exceções, como acontece nas microcirurgias, onde o campo operatório é exangue. Na casuística do presente estudo, a taxa de transfusão variou de 1,18\%, nos procedimentos com duração de até 60 minutos, até $50 \%$, nos procedimentos com duração superior a 780 minutos. Mais de $85 \%$ dos pacientes tiveram os seus procedimentos cirúrgicos realizados em tempo inferior a 4 horas e o índice de transfusão em procedimentos realizados dentro desta faixa de tempo foi de apenas 4\%. Foi possível estabelecer uma relação direta entre duração do procedimento cirúrgico e índice de transfusão sangüínea.

Considerando a técnica anestésica empregada, houve um índice de transfusão de $54,57 \%$ nos pacientes submetidos à raquianestesia combinada à anestesia peridural. Esta técnica tem sido utilizada com pequena freqüência (em 1999 ela foi utilizada em apenas 295 procedimentos), mas está indicada, na maioria das vezes, em procedimentos de maior duração. Com esta técnica se obtém as vantagens da raquianestesia, no tocante ao relaxamento muscular e é possível, ainda, deixar um cateter localizado no espaço peridural para complementação da anestesia ou tratamento da dor pósoperatória. Devido ao custo do material necessário para sua realização, a indicação esteve limitada a procedimentos mais complexos, daí o alto índice de transfusão. Cerca de 56\% dos pacientes foram submetidos à anestesia geral. A taxa de transfusão, neste grupo, foi de 9,73\%, em contraste com 1,30\% da raquianestesia e 1,78 da peridural. Nenhum paciente submetido a bloqueio de plexo braquial recebeu transfusão sangüínea. Isso pode ser facilmente explicado pelo uso do garroteamento em cirurgias do membro superior. Devido ao uso do garrote, as cirurgias de membro superior têm duração que não ultrapassa o tempo máximo permitido de utilização do garrote, que é de 60 a 90 minutos. Existem, dentre os 6126 pacientes submetidos a anestesia geral, pacientes que tiveram, associada a esta anestesia, uma anestesia espinhal (raquianestesia ou peridural). Isso aconteceu naqueles procedimentos de maior duração, já que a utilização de raquianestesia ou peridural por mais 
de 3 horas pode ser extremamente desconfortável para o paciente. A técnica anestésica pode influenciar a perda sangüínea em alguns tipos de procedimento. Em cirurgia de quadril, a anestesia regional está associada à menor perda sangüínea e à menor incidência de tromboembolismo (ROBERTS et al, 2000)

O anestesiologista, para indicar uma transfusão sangüínea no período intra-operatório, utiliza critérios clínicos e laboratoriais. O valor do hematócrito, embora não represente, com acurácia, a massa de células vermelhas no paciente com sangramento, é o critério laboratorial mais utilizado. Na casuística estudada, cerca de $40 \%$ dos pacientes foram transfundidos sem nenhuma avaliação laboratorial do valor da hemoglobina ou do hematócrito. Com relação à transfusão de plaquetas, o número de pacientes transfundidos sem avaliação do número de plaquetas previamente à transfusão chegou a $97 \%$.

O exame pré-operatório ou pré transfusional mais solicitado foi a quantificação do hematócrito, pela sua fácil execução (dentro do próprio centro cirúrgico) e pela importância desse parâmetro na indicação da transfusão, apesar dos fatores que podem influenciar o seu valor, como a quantidade de cristalóide administrada, por exemplo. Portanto, juntamente com a avaliação laboratorial, é mandatório que se realize também uma avaliação clínica do paciente (LICHTNSTEIN et al., 1988).

Os valores médios, obtidos nos exames préoperatórios foram 9,53 g/dl para a hemoglobina e 28,69\% para o hematócrito. Não foi possível avaliar, nesse trabalho, a perda sanguínea intraoperatória, que tem grande importância na indicação de transfusões sanguíneas, pelo fato desse registro não constar na quase totalidade das fichas de anestesia. Quanto à dosagem de plaquetas, obteve-se um valor médio de 56.166 plaquetas $/ \mathrm{mm}^{3}$. O valor limítrofe para a transfusão desse componente sangüíneo é de 50.000 plaquetas $/ \mathrm{mm}^{3}$, entretanto deve-se verificar se não existe uma plaquetopenia dilucional (CURCIO \& SOUZA, 1993).

A prática transfusional ainda hoje está calcada no conceito antigo de que só sangue substitui o sangue perdido (GONÇALVES et al, 1971). Dessa forma, se há sangramento profuso durante um procedimento, é comum que se inicie a reposição deste sangue perdido mesmo antes de se avaliar a relação risco/benefício. Nessa casuística apresentada, a reposição de glóbulos vermelhos não se baseou em critérios 
laboratoriais em 40\% dos casos. Enquanto que na reposição de plaquetas, em apenas 3\% dos pacientes que a receberam foi realizada sua contagem. Critérios clínicos podem e devem ser utilizados para nortear a indicação de uma transfusão, mas é necessário que esses critérios não se restrinjam à simples observação do campo operatório e volume armazenado nos frascos de aspiração. Uma das funções do sangue é carrear oxigênio para os tecidos. Sob circunstâncias normais, o sangue oferece cerca de 1000 mililitros de oxigênio por minuto para os tecidos e os tecidos consomem cerca de 250 mililitros de oxigênio por minuto, ou seja, oferece uma quantidade 4 vezes maior do que os tecidos consomem no mesmo intervalo de tempo (GREENBERG, 1995). Vários mecanismos compensatórios mantêm a oferta de oxigênio para os tecidos quando a quantidade de hemoglobina decresce no sangue: aumento do débito cardíaco, queda da pós carga por diminuição da resistência vascular periférica e da viscosidade sanguínea, bem como desvio da curva de dissociação da hemoglobina para a direita (HERBERT et al, 1997). Em pacientes cirúrgicos, que perdem sangue agudamente, a manutenção da volemia é crucial para que esses mecanismos de compensação funcionem, mas não se deve lançar mão, inicialmente, de sangue para repor o volume perdido.

A prática transfusional no meio cirúrgico, durante muito tempo, esteve centrada na regra 10/30, ou seja, os limites mínimos que desencadeariam a transfusão de glóbulos vermelhos seriam 10 g/dl de hemoglobina e 30\% de hematócrito (SPENCE et al, 1992; SPENCE et al, 1993; STEHLING \& SIMON, 1994). No passado, caso o paciente não apresentasse os valores mínimos preconizados pela regra 10/30, ele seria transfundido no período pré-operatório, mesmo que o procedimento cirúrgico fosse de baixo risco para sangramento. Atualmente, sabe-se que pacientes renais crônicos e anêmicos crônicos toleram valores de hemoglobina até abaixo de 7 g/dl. Em geral, preconizase a transfusão dos pacientes com valor de hemoglobina menor que $7 \mathrm{~g} / \mathrm{dl}$ e hematócrito menor que 21\%. Já os que apresentam valores de hemoglobina entre 7 a $10 \mathrm{~g} / \mathrm{dl}$ devem ser avaliados clinicamente. Da mesma forma, aqueles com hematócrito acima de 27 a 30\%, raramente necessitam de transfusão (Lundsgaard-Hansen, 1996) .

Na casuística apresentada, mesmo os pacientes que tinham hematócrito ou hemoglobina dentro de valores normais, receberam a transfusão de algum componente sangüíneo. Muitas vezes o exame é colhido e a transfusão iniciada antes 
do resultado do exame estar disponível. Mais de $20 \%$ dos pacientes transfundidos apresentavam nível de hemoglobina ou hematócrito dentro da faixa da normalidade.

Muito embora o sangue total não esteja disponível no Hemocentro de Ribeirão Preto, seu uso foi relatado em 69 fichas de anestesia (tabelas 23 e 25). Duas explicações podem existir para este fato: alguns pacientes receberam sangue total proveniente de pré-doação autóloga e isso não foi observado pelo anestesiologista, que acabou omitindo essa informação na ficha de anestesia ou o componente utilizado foi o concentrado de hemácias e o anestesiologista relatou, inadequadamente, como "sangue total”. Esta última hipótese é a mais provável, pois o Hemocentro fraciona o sangue proveniente de todas as doações. O uso do sangue total deve se restringir a algumas situações raras: hemorragias extensas em hepatopatas ou hemofílicos; plaquetopenia grave, transfusões maciças e distúrbios da coagulação (SPENCE, 1995). A transfusão de elementos específicos do sangue poupa os estoques dos Bancos de Sangue e não expõe o paciente a riscos desnecessários como incompatibilidade a células e proteínas plasmáticas presentes no sangue total Por outro lado, em caso de transfusão maciça, deve-se dar preferência ao sangue total em vez de se administrar concentrado de hemácias e plasma, separadamente, pois isso provoca a exposição do receptor a uma quantidade maior de doadores.

A maioria dos pacientes transfundidos com concentrado de hemácias recebeu de 301 a 508 mililitros, correspondente a aproximadamente duas unidades. Muitos pacientes são transfundidos, inicialmente, com duas unidades de concentrado de hemácias, muito embora sem uma constatação prévia da necessidade dessa quantidade do componente sangüíneo. Esse pensamento precisa ser revisto, pois uma unidade de concentrado de hemácias, muitas vezes, é suficiente para corrigir déficits de 1.500 a 2.000 mililitros de sangue (GLAZIER et al, 1998). Devemos ter em mente que a incidência de complicações infecciosas e não infecciosas está relacionada diretamente à quantidade de sangue transfundida e ao número de doadores necessários para suprir essa quantidade. Com o intuito de não se fazer transfusão desnecessária, LUNDSGAARD-HANSEN (1996) enfatiza a necessidade da realização do hematócrito antes de qualquer transfusão. Nesse aspecto, as transfusões realizadas no Hospital das Clínicas de Ribeirão Preto foram criteriosas, tendo em vista que o hematócrito pré operatório ou pré transfusional foi solicitado em 63\% dos 
pacientes que receberam algum componente sangüíneo e a dosagem de hemoglobina foi feita em 59,82\% dos pacientes transfundidos.

Em cinco casos, houve transfusão de mais de 3.000 mililitros de concentrado de hemácias, além de outros componentes sangüíneos: duas hepatectomias, duas exéreses de tumor cerebral e uma exérese de adenoma pleomórfico. Não houve, nestes pacientes, qualquer complicação decorrente da transfusão durante o período de internação hospitalar. A transfusão maciça é indicada para reposição volêmica, exsangüíneo transfusão (CARVALHO \& FERREIRA, 1985). Existem, porém, alguns riscos inerentes à transfusão maciça, como coagulopatia dilucional, hipotermia, hiperpotassemia, hipocalcemia, alterações hidroeletrolíticas e do equilíbrio ácido-básico decorrentes das mudanças sofridas pelo sangue estocado.

Dentre as complicações imediatas que podem ocorrer devido à transfusão sangüínea estão as reações hemolíticas agudas, por incompatibilidade com o sangue do doador, reações imunoalérgicas com quadros que vão desde reações urticariformes a broncoespasmo até edema agudo de pulmão e sobrecarga circulatória (VANE \& CASTIGLIA, 2000). Apenas uma destas complicações foi relatada nas fichas de anestesia: aparecimento de pápulas durante a infusão de plaquetas. Complicações tardias não foram avaliadas nesse trabalho.A transmissão de doenças infectocontagiosas por transfusão é detectada após alta hospitalar, tardiamente, quando da apresentação de sintomas ou por meio de achados eventuais em exames laboratoriais.

A utilização da auto-transfusão pré-operatória ou intra-operatória pode reduzir a freqüência da transfusão homóloga, mas em nenhuma ficha de anestesia essa técnica foi relatada. A hemodiluição normovolêmica aguda também contribui para a redução da incidência de transfusão de sangue homólogo (COPLEY et al, 1999). Nesta técnica, um determinado volume de sangue, previamente calculado, é retirado do paciente e armazenado na própria sala de cirurgia, por até 8 horas, e reinfundido após o término da fase de maior sangramento da cirurgia. O volume retirado é reposto com igual volume de solução coloidal ou volume triplicado de cristalóide. Com a manutenção da volemia, não ocorre desequilíbrio hemodinâmico e a perda de massa eritrocitária por volume de sangramento é menor. 
A transfusão autóloga não oferece risco de incompatibilidade, bem como de transmissão de doenças infecciosas (D’AMBRA \& KAPLAN, 1995). Kinoshita et al. (2000) concluíram que a transfusão autóloga diminui o risco de infecções pós-operatórias em cirurgias de câncer de esôfago e Cina \& Bruin (1999) demonstraram que a hemodiluição normovolêmica tem um efeito benéfico na hemostasia..

Roberts et al. (1996) fizeram uma interessante análise do custo de uma transfusão homóloga comparado à hemodiluição normovolêmica e ao pré depósito de sangue autólogo, concluindo que a diferença entre sangue homólogo e pré-depósito foi de U\$ 10.00 por unidade de concentrado de hemácias. Quando comparado com hemodiluição normovolêmica essa diferença aumentou para U\$ 62.52, demonstrando uma economia substancial com uso da hemodiluição.

Observa-se ainda que muitos pacientes (260) receberam papa de hemácias e plasma ao mesmo tempo. No Hospital das Clínicas de Ribeirão Preto não existe a disponibilidade de sangue total, exceto para alguns procedimentos específicos. Não foi possível avaliar o motivo das indicações da transfusão de plasma a partir das fichas de anestesias, mas é provável que muitas das razões para indicação dessa transfusão seja equivocada.

Apesar do amplo levantamento retrospectivo realizado, tivemos condição de apenas diagnosticar alguns dos problemas existentes na prática transfusional no Serviço de Anestesiologia do Hospital das Clínicas de Ribeirão Preto. Não foi possível estabelecer a porcentagem de transfusões inadequadas, já que os registros existentes nas fichas de anestesia foram insuficientes. Tivemos condição de analisar, exclusivamente, os parâmetros laboratoriais e descobrimos que cerca de $40 \%$ dos pacientes tiveram a indicação de transfusão baseada somente nos parâmetros clínicos. 
CONCLUSÕES 


\section{6 - CONCLUSÕES}

O Serviço de Anestesiologia do Hospital das Clínicas de Ribeirão Preto não apresenta um protocolo para indicação de transfusão sanguínea. Apesar de $60 \%$ das transfusões terem um exame laboratorial prévio, não houve relatos da estimativa de perda sangüínea no intraoperatório que indicassem um padrão de conduta, bem como um valor mínimo limítrofe para desencadear uma transfusão. 


\section{REFERÊNCIAS BIBLIOGRÁFICAS}




\section{7 - REFERÊNCIAS BIBLIOGRÁFICAS}

(De acordo com SIBI/USP e Malerbo \& Dias, 1994)

CARVALHO, A.F.; FERREIRA, J.J. Aspectos da transfusão maciça de sangue. Revista Brasileira de Anestesiologia, v. 35, p. 469-480, 1985.

CINA, C.; BRUIN, G. Acute normovolemic hemodilution (ANH) in surgery of the thoracoabdominal aorta. A cohort study to evaluate coagulation parameters and blood products utilization. J Cardiovasvc Surg, v. 40, p. 37-43, 1999.

COPLEY, L.A; RICHARDS, B.; SAFAVI, F.Z.; NEWTON, P.O. Hemodilution as a method to reduce transfusion requirements in adolescent spine fusion surgery. Spine, v. 24(3), p. 219-224, 1999.

CURCIO, K.; SOUZA, M. L. M. Sangue total e derivados: conceitos e critérios de uso. Revista Brasileira de Anestesiologia, v. 43, p. 1-9, 1993.

D’AMBRA, M.N.; KAPLAN, D.K. Alternatives to allogeneic blood use in surgery: acute normovolemic hemodilution and preoperative autologous donation. Am. J. Surg v. 170, p. 49S-52S, 1995.

FELICIO M. Transfusão de sangue e infusão de soluções balanceadas. Revista Brasileira de Anestesiologia, v. 30, p. 397-406, 1980.

GLAZIER, D.B.; CIOCCA, R.G.; GOSN, J.; MURPHY, D.P.; GRAHAM, A.M. Elective aortic surgery with minimal banked blood. Am. Surg, v. 64(2), p. 171-174, 1998. 
GONÇALVES, B.; SANTOS, C.B.; SPIEGEL, P. Problemas relacionados à transfusão de sangue. Revista Brasileira de Anestesiologia, v. 1, p. 86-99, 1971.

GREENBERG, A.G. A physiologic basis for red blood cell transfusion decisions. Am J Surg v. 170, p. 44S-48S, 1995.

HARMENING-PITTIGLIO, D. Técnicas modernas em banco de sangue e transfusão. 2nd ed. Rio de Janeiro, p. 1-24, p. 272-284, 1992.

HERBERT, P.C.; HU, L.Q.; BIRO, G.P. Review of physiologic mechanisms in response to anemia. Can Med Assoc. J. v. 156, p. S27-S40, 1997.

HESS, J.R. Blood substitutes. Semin Hematol v. 33, p. 369-378, 1996.

KINOSHITA, Y.; UDAGAWA, H.; TSUTSUMI, K.; UENO, M.; NAKAMURA, T.; AKIYAMA, H.; TAKAHASHI, K.; KAJIYAMA, Y.; TSURUMARU, M.Usefulness of autologous blood transfusion for avoiding allogenic transfusion and infectious complications after esophageal cancer resection. J. Surgery, v. 127, p. 185-192, 2000.

LIEHART, A.; AUROY, Y.; CLERGUE ,F.; LAXENAIRE, M.; PEQUIGNOT, F.; JOUGLA, E. La pratique de l'anesthésie en France en 1996. Anesthésie et techniques transfusionnelles. Ann Fr Anesth Réanim v. 17, p.1374-1386, 1998.

LICHTNSTEIN, A.; ECKHART, W.; SWANSON, K.; VACANTI, C.; ZAPOL, W. Unplanned intraoperative e postoperative hemodilution: oxygen transport and consumption during severe anemia. Anesthesiology, v. 69, p. 119-122, 1988. 
LUNDSGAARD-HANSEN P. Safe hemoglobin or hematocrit levels in surgical patients. World J. Surgery, v. 20, p. 1182-1188, 1996.

MALERBO, M.B.; DIAS M.B.Referências e citações bibliográficas: manual de orientação. Ribeirão Preto, BCRP-USP, 1994.

McCULLOUGH, J.; STEPPER, T.A.; CONNELLY, D.P.; JACKSON, B.; HUNTINGTON, S.; SCOTT, E.P. Platelet utilization in a university hospital. J.A.M.A. v. 259, p. 24142418, 1988.

MATHOULIN-PELISSIER, S.; SALMI, L.R.; VERRET, C.; DEMOURES, B. Blood transfusion in a random sample of hospitais in France. Transfusion, v. 40, p.1140-1146, 2000.

PORTER, R. The Cambridge illustrated history of medicine, Cambridge University Press, Cambridge, 1996. 400p.

PRICE STOVER, E.; SIEGEL, L.; PARKS, R.; LEVIN, J.; BODY, S.; FANZCA, C.B. Variability in transfusion practice for coronary artery bypass syrgery persists despeite National Consensus Guidelines. A 24 institution study. Anesthesiology, v. 88, p. 327333, 1998.

REMY, B.; DEBY DUPONT, G.; LAMY, M. Red blood cell substitutes: fluorocarbon emulsions and haemoglobin solutions. British Medical Bulletin, v. 55, p. 277-298. 1999. 
ROBERTS, M.; AHYA, R.; GREVES ,M.; MAFFULLI, N. A one centre prospective audit of peri-and postoperative blood loss and transfitsion practice m patients undergoing hip or knee replacement surgery. Ann R Coll Sur Engl, v. 82. p. 44-48, 2000

ROBERTS, W. A.; KIRKLEY, A.; NEWBY, M.. A cost comparison of allogeneic and preoperatively or intraoperatively donated autologous blood. Anesth Analg v. 83, p. 129-133, 1996.

SIRCHI, G.; GIOVANETTI, A.; McLELLAND, D.; FRACCHIA ,G. Safe and good use of blood in surgery (sanguis). Official Publications of the European Communities, Bruxelles, 1994: 1-235.

SPENCE, R. K Surgical red blood cell transfusion practice policies. Am. J. Surg. v. 170, p. 3S-15S, 1995.

SPENCE, R. K.; COSTABILE, J. P.; YOUNG,G.S. Is hemoglobin level alone a reliable predictor of outcome in the severely anemic patient ? Am Surg v. 58, p. 92-95, 1992.

SPENCE, R.K.; CERNAIANU, A.C.; CARSON, J.; DELROSSI, A.J. Transfusion and surgery Curr Probl Surg v. 30, p. 1101-1180, 1993.

STEHLING, L.; SIMON, T.L. The red blood cell transfusion trigger. Physiology and clinical studies. Arch Pathol Lab Med v. 118, p. 429-434, 1994. 
VAMVAKAS, E. Epidemiology of red blood cell utilization. Transfus. Med. Rev. v. 10, p. 44-61, 1996.

VAMVAKAS E.; TASWELL H. Epidemiology of blood transfusion. Transfusion, v. 34, p. 464-470, 1994.

VANE L. A.; CASTIGLIA Y. M. M. Uso de sangue autólogo. Depósito prévio, hemodiluição e recuperação celular. Anestesia de A a Z, v. 3, p. 6-14, 2000. 


\section{SUMMARY}


SUMMARY

\section{EVALUATION OF INTRAOPERATIVE TRANSFUSIONAL PRACTICE OF THE DEPARTMENT OF ANESTHESIA OF THE HOSPITAL DAS CLÍNCAS OF FACULTY OF MEDICINE OF RIBEIRÃO PRETO.}

A Survey was performed of 10.918 charts and respective medical records of patients submitted to anesthesia at the University Hospital, Faculty of Medicine of Ribeirão Preto from January to December 1999, in order to evaluate the conduct followed for hemotherapy.

The blood transfusion was performed in 809 (7,40\%) patients. There was relation between the incidency of transfusion and the duration of Surgery, but was not possible to establish any relation for different types of anesthesia. The pediatric and the geriatric were the patients who received transfusion more frequently.

The Department of Anesthesia of University Hospital, Faculty of Medicine of Ribeirão Preto has not a protocol for hemotherapy during anesthesia. 